\title{
The Mammalian Circadian Timing System: Organization and Coordination of Central and Peripheral Clocks
}

\author{
Charna Dibner, ${ }^{1}$ Ueli Schibler, ${ }^{2}$ and Urs Albrecht ${ }^{3}$ \\ ${ }^{1}$ Division of Endocrinology, Diabetes and Nutrition, Geneva University Hospital (HUG), \\ CH-1211 Geneva-14, Switzerland; email: charna.dibner@hcuge.ch \\ ${ }^{2}$ Department of Molecular Biology \& NCCR Frontiers in Genetics, Sciences III, \\ University of Geneva, CH-1211 Geneva-4, Switzerland; email: ueli.schibler@unige.ch \\ ${ }^{3}$ Department of Medicine, Division of Biochemistry, University of Fribourg, \\ CH-1700 Fribourg, Switzerland; email: urs.albrecht@unifr.ch
}

\section{Key Words}

SCN, robustness, circadian synchronization, FEO, MASCO, drugs and rhythms, reward system, circadian metabolism

\begin{abstract}
Most physiology and behavior of mammalian organisms follow daily oscillations. These rhythmic processes are governed by environmental cues (e.g., fluctuations in light intensity and temperature), an internal circadian timing system, and the interaction between this timekeeping system and environmental signals. In mammals, the circadian timekeeping system has a complex architecture, composed of a central pacemaker in the brain's suprachiasmatic nuclei (SCN) and subsidiary clocks in nearly every body cell. The central clock is synchronized to geophysical time mainly via photic cues perceived by the retina and transmitted by electrical signals to SCN neurons. In turn, the SCN influences circadian physiology and behavior via neuronal and humoral cues and via the synchronization of local oscillators that are operative in the cells of most organs and tissues. Thus, some of the SCN output pathways serve as input pathways for peripheral tissues. Here we discuss knowledge acquired during the past few years on the complex structure and function of the mammalian circadian timing system.
\end{abstract}




\section{INTRODUCTION}

SCN: suprachiasmatic nucleus
Most light-sensitive organisms from cyanobacteria to humans are equipped with timemeasuring devices, known as circadian clocks, that allow them to anticipate daytime and hence to organize their physiology and behavior in a proactive rather than a responsive manner. As insinuated by their name, circadian clocks ("circa diem" means "approximately a day") cannot measure $24 \mathrm{~h}$ with high precision but have to be periodically synchronized to geophysical time. The photoperiod is the most dominant environmental Zeitgeber (time giver) for the phase entrainment of circadian oscillators in all investigated organisms, including cyanobacteria, fungi, green plants, and metazoans. In mammals, the circadian timing system is composed of virtually as many clocks as there are cells, as most cells harbor selfsustained and cell-autonomous circadian oscillators. This raises the question of how light can establish phase coherence in cells of opaque organisms.

The answer lies in the hierarchical architecture of the mammalian timing system. Specialized suprachiasmatic nuclei (SCN) neurons receive photic information from the retina via synaptic transmission by axons of the retinohypothalamic tract. This electrical information is converted into chemical information that alters the phase of clock gene expression in a subset of SCN neurons. Because the oscillators of SCN neurons are tightly coupled (see Reference 1), the new phase is rapidly established in all SCN neurons. Owing to the paracrine and synaptic communication of SCN cells, the SCN oscillators never desynchronize in animals deprived of external timing cues. Moreover, the coupled SCN neurons maintain phase coherence during days to weeks in organotypic tissue explants (see Reference 1). The SCN then transmits its rhythmic information to cells in other brain regions and peripheral organs via a variety of outputs. These include neuronal connections, endocrine signals, body temperature rhythms, and indirect cues, provoked by oscillating behavior. For example, rest-activity cycles generate feeding-fasting rhythms, which appear to be dominant Zeitgebers for many peripheral organs, such as liver, pancreas, kidney, heart, and skeletal muscles. Although the molecular pathways through which feeding rhythms synchronize peripheral clocks are still poorly understood, it is tempting to speculate that nutrient-sensing hormones or intracellular metabolites may be involved. As revealed by studies on laboratory rodents and cultured cells, many parallel signaling pathways can reset the phase in peripheral cell types, and this redundancy renders the molecular dissection of these synchronization pathways particularly daunting. In this review, we discuss various routes by which the SCN may coordinate circadian physiology in the brain and peripheral tissues.

\section{CENTRAL CLOCKS AND THE BRAIN}

As mentioned above, the circadian system of mammals encompasses all organs, tissues, and cells. One of the hallmarks of this system is its ability to synchronize the individual circadian clocks at all levels. The brain, however, has a somewhat special position because it is separated by the blood-brain barrier from the rest of the body. As a consequence, synchronization mechanisms that coordinate peripheral organs and tissues do not necessarily have the same effect on the brain. Only nervous signals and blood-borne lipophilic signaling molecules such as glucocorticoids, which can pass through the blood-brain barrier, can affect the brain.

Synchronization between central and peripheral clocks and synchronization of cellular clocks within the brain impact circadian timing, physiology, and behavior. In the following sections we discuss different oscillators in the brain and their function.

\section{Suprachiasmatic Nuclei: Master Clock or Master Synchronizer?}

Initially, circadian rhythms were seen as a diffuse time-measuring capacity of the organism as a whole, until Pittendrigh (2) developed the 
idea of a distinct light-sensitive oscillator that serves as a pacemaker for the organism. From then on researchers were investigating brain structures that could serve as pacemakers, mainly using wheel-running behavior of laboratory rodents as a readout. Lesion experiments in the brain led to the identification of a paired structure in the hypothalamus located just above the optic chiasma, the SCN (Figure 1). This structure appeared to be important for rhythmicity in corticosterone secretion and locomotor activity $(3,4)$. Transplantation of fetal SCN tissue into the third ventricle of previously SCN-lesioned hamsters restored circadian

Figure 1

(a) Main afferent pathways to the SCN in rat. Orange arrows represent photic input, and blue arrows represent nonphotic input to the SCN. 5-HT, serotonin; DRN, dorsal raphe nucleus; IGL, intergeniculate leaflet; GABA, gamma-aminobutyric acid; GHT, geniculohypothalamic tract; Glu, glutamate; MRN, median raphe nucleus; NPY, neuropeptide Y; PACAP, pituitary adenylate cyclase-activating peptide; RHT, retinohypothalamic tract; SCN, suprachiasmatic nuclei. (b) Efferent pathways from the SCN (red) to hypothalamic (yellow) and thalamic (green) brain regions. AMY, amygdala; ARC, arcuate nucleus; BNST, bed nucleus of the stria terminalis; $\mathrm{DMH}$, dorsomedial hypothalamus; $\mathrm{HB}$, habenula; IGL, intergeniculate leaflet; LS, lateral septum; POA, preoptic area; PVN, paraventricular nucleus of the hypothalamus; PVT, paraventricular nucleus of the thalamus; SCN, suprachiasmatic nuclei; sPVZ, subparaventricular zone. (c) Pathways from the PVN to the adrenal gland. Three different output systems are highlighted: the neuroendocrine neurons of the PVN-controlling pituitary (Pit) hormones (blue arrows), parasympathetically projecting neurons in the PVN that target the dorsal motor nucleus of the vagus (DMV) (purple arrow), and sympathetically projecting neurons in the PVN that target the spinal cord preganglionic neurons located in the intermediolateral columns (IML) (red arrows). From the IML the pineal gland (Pin) is regulated via the superior cervical ganglia (SCG). The neuronal message sets the sensitivity of the organs for the arrival of hormones. The neuronal and hormonal messages from the organs feed back to the brain. $\mathrm{ME}$, median eminence. ACTH, adrenocorticotropic hormone; CRH, corticotropin-releasing hormone; AVP, arginine vasopressin. locomotor activity (5). Furthermore, SCN tissue from Tau mutant hamsters displaying circadian rhythmicity with a shortened period length restored rhythms in SCN-lesioned wild-type hamsters with a period length characteristic of the mutant donor (6). Similarly, SCN grafts from wild-type mice could restore
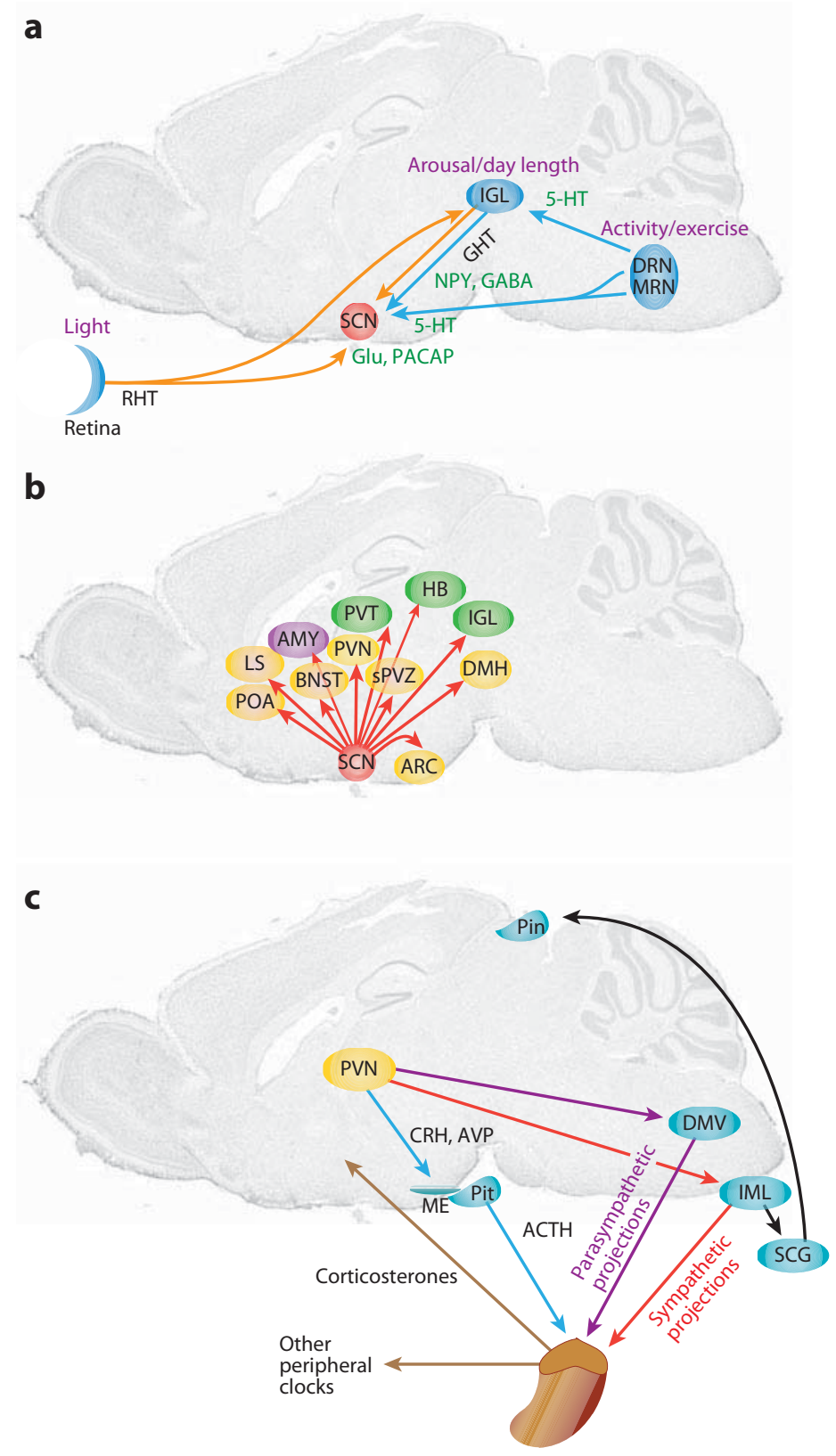
RHT:

retinohypothalamic

tract

GHT:

geniculohypothalamic

tract

pRGC:

photosensitive retinal

ganglion cells

VIP: vasoactive intestinal polypeptide

PACAP: pituitary adenylate cyclaseactivating protein circadian rhythmicity in genetically arrhythmic mice (7). These experiments demonstrated a prominent role of the SCN for circadian rhythmicity. When the SCN were isolated as a hypothalamic "island" (8) or when SCN neurons were cultured in vitro, electrical activity was circadian (9-11), even after three weeks in culture (12). Furthermore, individual neurons showed circadian firing rhythms, demonstrating the cellular nature of circadian rhythms (13). Additionally, metabolic activity and glucose uptake in the SCN were dependent on time (14) as well as on expression of clock genes $(15,16)$ and proteins (17), illustrating clock activity in the SCN at the physiological and molecular levels.

The above-mentioned observations led to the view that the SCN are containing the clock of an organism and that other rhythms may be simply driven by this master clock in the brain, because secretion of vasopressin, one of the peptides transmitted by the SCN, followed the SCN's pattern of electrical and metabolic activity. However, there was evidence that oxygen consumption in rat liver suspension culture was circadian (18), indicating the presence of self-sustaining clocks in the periphery. This notion has been substantiated, leading to the view that a self-sustained clock not only is a property of the SCN and its neurons but is present in most, if not all, tissues, organs, and cells (see below). Therefore, the SCN is probably best viewed as a conductor of an orchestra of clocks that synchronizes all clocks and integrates information from the periphery to generate coherent systemic rhythms in the organism.

\section{The Suprachiasmatic Nuclei: A Relay to Synchronize Physiology to Environmental Changes}

To adapt an organism's physiology to changing environmental parameters, information from outside has to reach body structures that can integrate this information and send appropriate signals to various tissues. The SCN have the capacity to serve as such a relay between the external and internal worlds and the body (Figure 1).

Input to the SCN: information from the environment. The SCN can be influenced via three major input pathways: the retinohypothalamic tract (RHT), the geniculohypothalamic tract (GHT), and serotonergic (5HT) input from the dorsal raphe nucleus (DRN) and median raphe nucleus (MRN) (Figure 1 $\boldsymbol{a}$ ). From these three input pathways the RHT mediates photic information (Figure 1a), whereas the GHT and the raphe nuclei provide nonphotic information to the SCN (Figure 1 $\boldsymbol{a}$ ). The SCN vary in their temporal responsiveness to these stimuli. For example, in nocturnal rodents, exposure to light causes shifts in the phase of the SCN clock primarily during subjective night (the activity period in rodents), whereas nonphotic cues elicit these shifts mainly during the subjective day (the resting period in rodents).

Mammals perceive light information mainly via the retina of the eye, where non-imageforming photoreceptors termed photosensitive retinal ganglion cells (pRGC) (19-21), which express the photopigment melanopsin [a homolog of a photoreceptor in amphibian skin (22-24)], send photic information directly to the SCN via the RHT (25). The monosynaptic RHT fibers end directly on neurons in the ventrolateral part of the SCN that express vasoactive intestinal polypeptide (VIP) $(26,27)$. The molecules implicated in the photic signaling are the excitatory neurotransmitter glutamate (28) and the neuropeptide pituitary adenylate cyclase-activating protein (PACAP) (29). Their release leads to the activation of several signaling pathways (reviewed in Reference 30) and evokes chromatin remodeling (31) and induction of clock genes (32-34) and immediate early genes (35). One important signaling mechanism for transmitting light information in an SCN neuron involves $\mathrm{Ca}^{2+}$ influx and intracellular $\mathrm{Ca}^{2+}$ levels modulated by the inositol trisphosphate receptor (36) and the ryanodine receptor (37). Regulation of the ryanodine receptor appears to involve circadian clock proteins in vitro (38), providing evidence that the 
clock may regulate components of its own input pathway. Recently, a role of inbibitor of $D N A$ binding (Id) genes in the regulation of photic entrainment of the mammalian clock has been proposed (39). In particular, Id2 can inhibit CLOCK:BMAL1 transactivation of Per1 and AVP (arginine-vasopressin) promoters in vitro.

However, the most extensively studied pathway is the extracellular signal-regulated kinase (ERK) pathway. Activation of ERK culminates in the phosphorylation of cAMP response element-binding (CREB) protein (40-42). Phosphorylated CREB binds to cAMP response elements (CRE) located in the promoters of target genes, activating their transcription (43). Per 1 and Per 2 genes contain a CRE within their promoter regions; hence, these core clock genes can be activated independently of the CLOCK:BMAL1-controlled E-box activation $(44,45)$. Interestingly, these genes are inducible only when light hits the retina during the night (or subjective night, when animals are kept in constant darkness), which is during the time when mammals respond behaviorally with an advance or a delay of periodic activity. This adaptation is termed resetting and probably reflects the necessity of daily adaptation of the internal clock to the current solar time. Per1 gene induction appears to play an important role in the resetting process because antisense oligonucleotides against Per1 inhibit phase delays (46) and phase advances (47). Similarly, photic induction of the Per 2 gene may be involved in phase delays (48). Consistent with these observations is the finding that light-dependent phase advances or delays are impaired in mice mutant in the Per 1 or Per 2 genes, respectively (49). However, it appears that behavioral responses to light are strongly dependent on the light history that an organism experienced $(50,51)$.

Interestingly, the RHT projects not only to the SCN but also to the intergeniculate leaflets (IGL) (Figure 1a) $(52,53)$. From the IGL the GHT projects to the SCN and therefore can indirectly confer processed light information by releasing neuropeptide Y (NPY) and gammaaminobutyric acid (GABA) $(52,54)$. Hence, the
SCN receive two different signals upon light stimulation of the retina, one directly via the RHT and the other indirectly via the GHT. The delay between the RHT and the GHT signals may provide additional information leading to a more differentiated response of the SCN to light. This may partially explain the importance of light history in molecular and behavioral responses. Consistent with this view are the observations that the IGL modulates photoperiod responsiveness in Siberian hamsters (55) and that NPY-deficient mice show altered circadian response to simulated "natural" photoperiods (56). The IGL, however, is stimulated not only via the RHT from the retina but also via a nonphotic pathway emanating from the DRN (57) (Figure 1a). This indicates that the pathway via the IGL allows an integration of photic and nonphotic signals to entrain the SCN.

The third important afferent input to the SCN comes from the MRN in hamsters (57, 58) and from both the MRN and DRN in rats (59) (Figure 1 $\boldsymbol{a}$ ). These fibers end within the VIP-immunoreactive cells of the SCN core region $(60,61)$, to which the retinal afferents also project (62). When this 5HT path is influenced by administration of agonists or antagonists of 5HT, locomotor activity in both light-dark (LD) and dark-dark (DD) is affected (63). Therefore, it is believed that the $5 \mathrm{HT}$ tract participates in nonphotic regulation of the SCN and entrainment of the circadian clock.

Output from the SCN: passing information to the body. To function as a pacemaker and synchronizer for other brain and peripheral clocks, the intrinsic timekeeping signal from the SCN has to be transmitted. In the brain, the connections of the SCN with other brain structures have been elucidated by injecting antero- and retrograde tracers showing that the SCN efferents terminate in a range of brain sites (Figure 1b) (64). Within the hypothalamus SCN efferents terminate most densely in the subparaventricular zone (sPVZ) (65) and rostrally in the preoptic area (POA), the bed nucleus of the stria terminalis (BNST), and the
CREB protein: calcium/cAMP response elementbinding protein

LD: light-dark

DD: dark-dark 
DMH: dorsomedial hypothalamus

ARC: arcuate nucleus

PVN: paraventricular nucleus

HB: habenula lateral septum (LS). Dorsally, they terminate in the dorsomedial hypothalamus (DMH) and the arcuate nucleus (ARC). In the thalamus, axons from the SCN innervate the paraventricular nucleus (PVN) and possibly the IGL. Other SCN projections like those to the habenula $(\mathrm{HB})$ and amygdala (AMY) have to be confirmed. Of note, specific subdivisions within the SCN project to designated areas, and these patterns of projections can differ between species (reviewed in References 66 and 67).

Neurochemicals transmit SCN information via the axonal connections mentioned above. Ultrastructural studies have shown that 30\% of SCN axons contain both GABA and peptide neurotransmitters $(68,69)$. Electrophysiological studies have also shown that glutamate is an SCN transmitter (70) and conveys circadian signals to hypothalamic target structures (71). Additionally, the following molecules have been described as SCN output signals: AVP (72), cardiolipin-like cytokine (73), prokineticin 2 (PK2) (74), VIP (75), and transforming growth factor $\alpha(\mathrm{TGF} \alpha)(76,77)$. For some of these neurochemicals, rhythms of synthesis in the SCN have been observed. However, it is unclear whether mRNA rhythms result in cyclical release of these transmitters in the target sites of SCN efferents.

The best studied of these candidate outputs is PK2. In the SCN its expression peaks in the middle of subjective day, and this pattern of expression is altered by light exposure (78). PK2 receptor mRNA expression is observed in many brain areas known to receive SCN efferents including the DMH, the LS, and the PVN (Figure 1b). Exogenous application of PK2 suppresses locomotor activity in rats during the night but increases it during the day, indicating that PK2 transmits circadian activity of the SCN $(74,79)$. However, mice lacking PK2 or the $\mathrm{PK} 2$ receptor display dampened rhythms in activity and thermoregulation, suggesting that factors other than PK2 can sustain circadian locomotor activity $(80,81)$.

The transplantation experiments of SCN tissue described above make evident that projections from SCN neurons are not required for the establishment of locomotor activity rhythms. Transplanted SCN tissue can be implanted into many brain areas and restore rhythms, as can fetal SCN grafts encapsulated in material preventing neurite outgrowth into the host brain (82). Thus, it appears that an asyet-unknown paracrine factor(s) released from SCN tissue can act to coordinate the expression of rhythms in wheel-running activity. The site of action of these factors is unknown, but lesion experiments suggest that the $\mathrm{PVVZ}$ is involved. Interestingly, SCN grafts do not restore rhythms in the neuroendocrine axis. This implicates that SCN efferents control hormone rhythms such as melatonin and corticosterone $(5,83)$.

Hence, the autonomic nervous system plays an important role as a hand of the SCN master pacemaker. In support of this view are data suggesting that the SCN controls (indirectly; see Figure 1c) pineal as well as adrenal cortex function. Tracing studies and physiological experiments indicate that, apart from the classical neuroendocrine control of the adrenal cortex by the PVN-CRH-ACTH (paraventricular nucleus-adrenocorticotropic hormonecorticotropin-releasing hormone) cascade, the autonomic projections of the SCN via the PVN to the IML determine daily changes in sensitivity of the adrenal gland to ACTH $(71,84$, $85)$. This is further highlighted by the finding that light activates the murine adrenal gland, as observed via timing of gene expression and glucocorticoid release (86). Moreover, light affects gene expression via the autonomic nervous system in the liver (87). It appears that the SCN affect not only hormone secretion but also modulate the sensitivity of the target organs of these hormones by neuronal mechanisms. This notion is supported by the finding that injection of transneuronal tracers into various organs/tissues results in the labeling of neurons in the SCN via sympathetic and parasympathetic branches of the autonomic nervous system (88-91). Because neurons in the SCN are labeled via both the parasympathetic and the sympathetic systems, the SCN probably influences both the rest and the activity periods of 
circadian rhythms. Taken together, the data indicate that the SCN can transmit circadian information to influence cyclic physiology in peripheral organs not only by hormones but also by direct nervous control of these organs (reviewed in Reference 92).

The findings described above have to be taken with a grain of salt. Although most mammals show circadian rest/activity patterns, some are nocturnal and others diurnal. Hence, hormonal signaling as well as neuronal projections may differ between such organisms. However, in the SCN there is no distinction between nocturnal and diurnal animals with regard to the phase of clock gene expression because the light-dependent synchronization is similar in all investigated species $(93,94)$. Examination of the mRNA profile of the putative output factor TGF $\alpha$ in the SCN showed that in the diurnal rodent Arvicanthis ansorgei the pattern of expression does not match the behavioral rhythm, whereas it does in nocturnal animals (95). Furthermore, the phase of circadian gene expression varies greatly in peripheral tissues of diurnal and nocturnal animals (96). Therefore, the signals emanating from the SCN must be interpreted in an opposite manner in diurnal compared with nocturnal mammals. One plausible explanation for these observations is that the downstream actions of SCN output factors differ between nocturnal and diurnal animals. Identification of such factors will be of great interest to the field of chronobiology.

\section{Multiple Brain Clocks: Multiple Clock Mechanisms?}

The first autonomous oscillator in mammals outside the SCN was identified in the retina (97). Cultured retina displayed circadian rhythms in melatonin synthesis that entrained to light in vitro, continued oscillating in constant darkness, and were temperature compensated, all hallmarks of an autonomous oscillator. Cultured retina from Tau mutant hamsters showed an accelerated circadian melatonin rhythm of $20 \mathrm{~h}$, which paralleled the period of locomotor rhythms in these hamsters
$(97,98)$, indicating that the oscillations in the retina are generated by similar mechanisms as in the SCN. Interestingly, reports on clock gene expression in the retina are contradictory with regard to the pattern and phase of oscillating gene expression. This hints to variations in the clock mechanism that may depend on tissueor species-specific factors. For example, a variation in the clock mechanism is observed in the forebrain of mice, where NPAS2 acts as a functional substitute for CLOCK $(99,100)$. As revealed by loss-of-function genetics, NPAS2 and CLOCK can functionally replace each other in the SCN. In contrast, CLOCK is indispensable for circadian gene expression in peripheral tissues (101).

The discovery of clock genes enabled the identification of brain areas that contain the molecular machinery necessary for the generation of circadian rhythms. Thus, daily oscillations in gene expression have been identified in a number of brain regions (102), including nuclei in the thalamus and hypothalamus, $\mathrm{AMY}$, olfactory bulbs (OB), and cerebellum (see Figure 2) (for a comprehensive list, see Reference 103). Transgenic rats expressing the luciferase gene under the murine Per 1 promoter allowed visualization of intrinsic rhythmicity of Per1 promoter activation in isolated brain regions (104). Twenty-seven different brain regions were cultured, and approximately half were rhythmic. The SCN displayed sustained circadian Per1 bioluminescence, whereas all other brain regions investigated showed dampened oscillations or were arrhythmic. This finding is in keeping with the observations that the cellular oscillators are coupled in the SCN but not in other brain regions (or peripheral tissues; see Reference 1). From the extra-SCN oscillators the OB (Figure 2) showed the most robust rhythms, and tissues with a neuroendocrine function such as the ARC, PVN, and pituitary gland (Pit) displayed only slight dampening of bioluminescence over time. Maximal Per1 promoter activity was observed during the day in the SCN, but not in other brain regions. Thus, notable differences in phase and robustness as well as in the kinetics of light-induced
OB: olfactory bulbs 


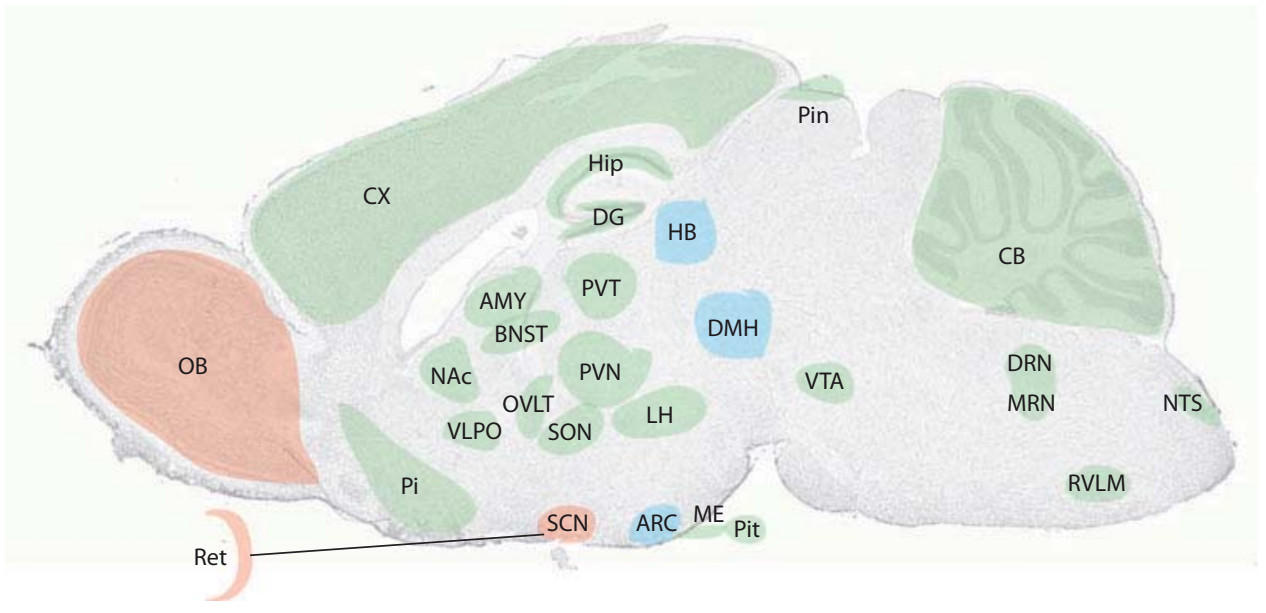

Figure 2

Potential circadian oscillators in the mammalian brain. Self-sustained circadian oscillators are shown shaded in red, semiautonomous oscillators in blue, and slave oscillators in green. AMY, amygdala; ARC, arcuate nucleus; BNST, bed nucleus of the stria terminalis; CB, cerebellum; CX, cortex; DG, dentate gyrus; $\mathrm{DMH}$, dorsomedial hypothalamus; DRN, dorsal raphe nucleus; HB, habenula; Hip, hippocampus; LH, lateral hypothalamus; ME, median eminence; MRN, median raphe nucleus; NAc, nucleus accumbens; NTS, nucleus of the solitary tract; OB, olfactory bulb; OVLT, vascular organ of the lamina terminalis; $\mathrm{Pi}$, piriform cortex; Pin, pineal gland; Pit, pituitary gland; PVN, paraventricular nucleus of the hypothalamus; PVT, paraventricular nucleus of the thalamus; Ret, retina; RVLM, rostral ventrolateral medulla; SCN, suprachiasmatic nuclei; SON, supraoptic nucleus; VLPO, ventrolateral preoptic area; VTA, ventral tegmental area.

phase resetting exist between different brain areas $(104,105)$. Attenuated oscillations in extra-SCN brain rhythms may be attributable to either a lower robustness of oscillators in individual cells or a less efficient synchronization of individually oscillating cells. Fibroblasts kept in culture display robust oscillations, but because individual cells have slightly different periods, they desynchronize over time. Hence, after a transient synchronization by a serum shock or a dexamethasone treatment, oscillations of gene expression in the entire population dampen after a few days $(106,107)$. Similarly, in cultured $\mathrm{OB}$, individual neurons display circadian oscillations in Per1:luciferase expression that differ in phase and periods, and therefore the compound rhythms of $\mathrm{OB}$ are lost over time (108). In the intact animal, signals from the SCN appear to synchronize populations of weakly coupled or noncoupled cells in the brain, rather than impose rhythmicity on otherwise arrhythmic cells in non-SCN brain regions.
The brain is composed of various cell types; neurons and glia are the most prominent ones. Neurons and glia are metabolically dependent on each other (109) and have complementary functions. The degree of metabolic dependency as well as the electophysiological communication between these two cell types may vary in different brain regions, which may have consequences on the degree of synchronization between these cells. Therefore, it is important to evaluate whether the circadian clock mechanism as well as the synchronization properties of these two cell types in the brain are identical. A recent study evaluated the expression of the clock genes Per 1 and Per2 using mice expressing the Venus and DsRED proteins under the control of the Per 1 and Per 2 promoters, respectively (110). Consistent with previous observations (102), the expression of the Per 1 and Per 2 transgenes was only partially overlapping in various brain regions. Detailed cellular analysis in the dentate gyrus (DG), striatum, and 
cortex revealed that Per2:DsDRED is mainly observed in cells expressing glial fibrillary acidic protein (GFAP), a marker for glial cells. In contrast, Per1:Venus is expressed in neurons and to some extent also in glial cells (110). These results indicate cell type-specific segregation of Per 1 and Per 2 promoter activation, suggesting a possible divergent role of Per 1 and Per 2 in mouse brain, as suggested previously on the basis of microarray data (111). Furthermore, these results indicate that variations in the clock mechanism in neurons and glia may exist. In line with this view is the observation that Per 2 mutant mice have a specific defect in astrocytes (a glial cell type). In these animals the astrocyte-specific glutamate transporter Eaat1 (Glast) is reduced in its expression, and as a consequence uptake of glutamate by astrocytes is reduced, leading to an inefficient clearance of glutamate from the synaptic cleft (112). Future experiments will hopefully shed light on the importance of the segregation of Per 1 and Per 2 gene activation in the two main cell types in the brain and the impact such segregation may have on intercellular coupling and cell-autonomous oscillations.

In the brain, the functional relevance of circadian clock gene expression can be measured by evaluating the firing rate of neurons. In the SCN, similar periods of clock gene expression and firing rates are observed. In particular, Per1 transcription positively correlates with firing rate in a linear fashion in Per1:GFP (green fluorescent protein) mice (113). In vasoactive intestinal peptide receptor 2 (VPAC2) receptor-deficient mice, Per1, Per2, and Cry 1 gene expression is attenuated in the SCN (114), and similar blunted rhythms are observed in the cellular excitability in these animals (115-117). However, it is unclear whether all extra-SCN brain regions translate clock gene expression cycles into physiologically relevant firing rate rhythms. Cell firing activities outside the SCN were evaluated in several studies (118), but only a few of the brain areas, including the $\mathrm{OB}$ and the lateral $\mathrm{HB}$, maintained electrical rhythms and oscillating clock gene expression in the absence of the SCN $(105,108,119)$.
An independent self-sustained circadian oscillator in the $\mathrm{OB}$ may be important to regulate the sensitivity level of olfactory neurons, thus allowing an animal to follow an odor concentration gradient toward a food source in a daytimedependent manner. Likewise, increased responsiveness to stimulatory signals from potential mates may be advantageous. The HB has been proposed to contain at least a semiautonomous oscillator (119). Because the HB receives direct nonvisual projections from the retina (120), and because together with the nucleus accumbens (NAc) (121) the HB projects to the pineal gland, the raphe nuclei, the substantia nigra, and the ventral tegmental area (VTA) (122-125), the HB may be important in the integration of diurnal signals to regulate reward-related behavior. SCN-independent oscillators in particular brain regions may help an animal to temporally coordinate its basic needs, such as feeding and mating.

\section{Brain Clocks, Drugs, and the Reward System}

Brain structures that regulate and control behavior by inducing pleasurable effects make up the reward system. These structures include, among others, the VTA, the NAc, the HB, and the prefrontal cortex. The presentation of a reward more than once reinforces the intensity of a given behavior. Primary rewards are elicited by food, water, and sex, which are all necessary for survival of the individual and/or species. Secondary rewards derive their values from primary rewards and, for humans, include music, pleasant touch, and money. Rewards modify behavior, modulate learning capabilities, and influence mood. For example, food, alcohol, and cocaine positively influence the reward system, improve subjective well-being, and encourage repetitive ingestion, which will eventually lead to a compulsive behavior. Such reward-related behavior exhibits a recurring pattern with a period of approximately $24 \mathrm{~h}$ (126-130), indicating an interaction between the circadian and the reward systems in the brain. Seasonal patterns also appear to influence the use of 
addictive drugs such as alcohol, which is often accompanied by depression (131). This seasonal incidence of affective illness is reflected in biochemical determinants (132), suggesting a cellular and molecular basis of such disorders. In support of this view are observations that humans with genetically determined sleep disorders are more prone to addiction (133). Rats with an abnormal circadian rhythm and mice with a mutation in the Per 2 gene absorb ethanol at increased levels when simultaneously offered pure drinking water and a dilute solution of alcohol (112, 134).

Further evidence for the involvement of clock components in drug-induced behavior comes from mice with disrupted Per 1 or Per 2 genes. In these animals locomotor sensitization and conditioned preference for cocaine are abnormal (126). Furthermore, expression of these genes is induced by cocaine in the dorsal striatum and the NAc, brain regions important for cocaine-mediated behavioral effects $(135,136)$. Interestingly, cocaine differentially affects expression of clock genes in the brain, depending on the treatment schedule (acute or chronic) and the brain area (137). Cocaine and other drugs of abuse such as methamphetamine (see below) influence the reward

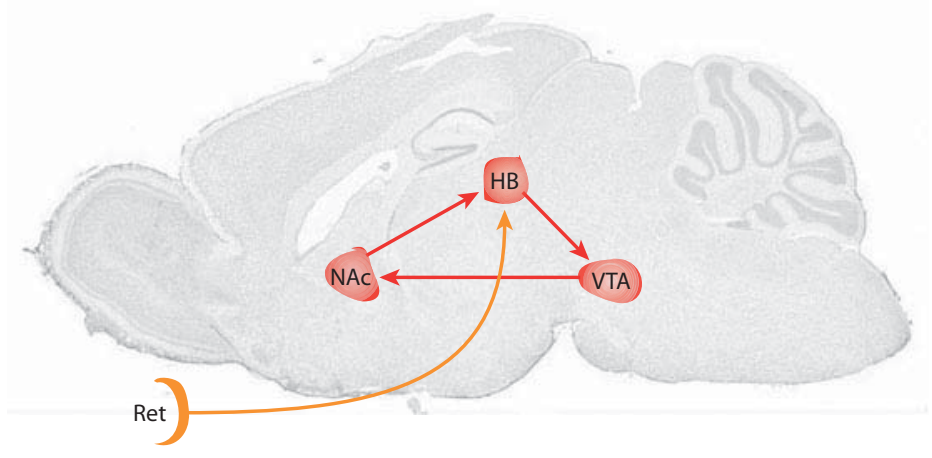

Figure 3

A potential role of the habenula $(\mathrm{HB})$ in the reward system. The ventral tegmental area (VTA)-nucleus accumbens (NAc) pathway plays a critical role in reward. Dopaminergic projections innervate the NAc. How much stimulation from the VTA reaches the NAc may be influenced by the HB, which signals to the VTA when no reward is expected. The NAc in turn feeds back to the HB, thereby establishing a regulatory circuit balancing dopamine levels in the brain. Direct light input to the HB may influence dopamine balance and adjust it to the diurnal cycle. Ret, retina. system in part by modulating dopamine neurotransmission in the mesolimbic dopamine reward circuit, including the VTA and NAc of the striatum $(138,139)$ (Figure 3). Several interactions between dopamine and the circadian clock have been reported. Dopamine neurons in the retina regulate adaptation to light (140), and dopamine D2 receptor-null mice show impaired light masking (141). Signaling via the dopamine D2 receptor also potentiates circadian transcriptional regulation in the retina (142). Mice with a point mutation in the gene Clock display increased excitability of dopamine neurons, cocaine reward, and expression of tyrosine hydroxylase, the rate-limiting enzyme in dopamine synthesis (143). Furthermore, these animals display a mania-like phenotype similar to that observed in patients with bipolar disorder (144). A molecular link between the circadian clock mechanism and dopamine metabolism has just recently been established (145). In mice, the clock proteins BMAL1, NPAS2, and PER2 regulate expression levels and activity of monoamine oxidase A (MaoA), an enzyme important in dopamine degradation. In this mechanism, PER2 acts as a coactivator and modulates dopamine levels in the mesolimbic dopaminergic system. This has an impact on mood-related behavior in mice, leading to the conclusion that the clock can influence mood. In support of this conclusion is that seasonal affective disorder (SAD) in humans correlates with the frequency of specific single-nucleotide polymorphisms in BMAL1, NPAS2, and PER2 (146).

Methamphetamine-sensitive circadian oscillator (MASCO). The influence of drugs of abuse on circadian behavior was first studied in rats (147) by using methamphetamine [(2S)- $N$-methyl-1-phenylpropan-2amine]. Methamphetamine affects locomotor activity, the length of alpha (the duration between onset and offset of daily activity), and the period length of the activity rhythm. Even in constant darkness, these effects persist but disappear after withdrawal of methamphetamine. Interestingly, methamphetamine can induce 
robust activity rhythms in SCN-lesioned rats (148) as well as in Clock and Cry1/Cry2 mutant mice that are arrhythmic under constant darkness conditions $(149,150)$, suggesting that an oscillator that is independent of the SCN and is sensitive to methamphetamine must exist. All the behavioral responses observed in rats were confirmed in mice, and these effects do not depend on rhythmic consumption of methamphetamine, indicating that a methamphetamine-sensitive circadian oscillator (MASCO) also exists in mice (151). Because methamphetamine acts primarily on dopaminergic cells in the brain, the mesolimbic-dopaminergic system (VTA, NAc, striatum) (see Figure 3) is probably affected by this drug. This would lead to alterations in dopamine (or other catecholamine) levels in the brain.

At the molecular level, repeated injections of methamphetamine cause a sensitized increase in Per1 gene expression specifically in the mouse striatum without affecting Per1 or Per 2 gene expression in the master clock of the SCN (152). Furthermore, acute injection of methamphetamine increases the expression of Per1, Bmal1, and Npas2 genes in the striatum. Additionally, chronic daytime methamphetamine treatment shifts rhythmic Per1 and Per2 expression in the striatum from a nocturnal to a diurnal rhythm without affecting the rhythm in the SCN (153). Among genes altered in expression by methamphetamine treatment, the clock gene Per2 was most affected (154). Interestingly, mutation of the Per 2 gene leads to a reduction of dopamine degradation (155), highlighting the mutual interaction of the circadian clock with dopamine levels in the striatum. This suggests that known clock components either are part of the MASCO or link the MASCO to the regular circadian oscillator (RCO). In favor of the second possibility are the findings that all clock gene mutants having methamphetamine in their drinking water can display rhythmic behavior with a period length of between 25 and $37 \mathrm{~h}$, even when the SCN is surgically removed (156). Therefore, one can hypothesize that some clock components are involved in coupling the long-period MASCO to the shorter-period RCO to bring the two into resonance. The molecular makeup of the MASCO remains to be investigated.

Because it appears that the MASCO is an SCN-independent oscillator, the question arises as to what the anatomical substrate for MASCO might be. A $\mathrm{Mn}^{2+}$-enhanced MRI study revealed neuronal dysfunction of a longprojecting multisynaptic pathway in response to methamphetamine after injection of $\mathrm{Mn}^{2+}$ in the HB (157). This pathway includes the VTA, striatum, and NAc, which as discussed above make up the mesolimbic dopaminergic system. Hence, it appears that methamphetamine affects the mesolimbic dopaminergic system (Figure 3), in which dopamine degradation is at least in part under circadian clock control (155). But what role does the $\mathrm{HB}$ play? A recent investigation shows that neurons in the lateral $\mathrm{HB}$ signal to dopamine neurons when no reward is expected (158). This finding is of great importance because the firing rate of dopamine neurons increases when a reward is given unexpectedly and decreases when an expected reward is omitted. This firing has been proposed to reflect reward prediction errors, a parameter that reflects the difference between the expected as opposed to the actually obtained reward value (159). Thus, the lateral HB seems to be critically involved in predicting reward. Because the $\mathrm{HB}$ is directly innervated by the retina (120), it has the possibility, at least theoretically, of relating reward with the day/night cycle and thus modulating behavior toward maximal efficiency for obtaining a reward such as food. In a natural setting, this is of utmost importance for an animal to survive in a competitive environment.

Food-entrainable oscillator (FEO). When food availability is limited to a few hours during each day, mammals quickly alter daily rhythms of physiology and behavior, such as locomotor activity, body temperature, and corticosterone secretion, to correlate with the food availability rhythm (160-162). Increases in locomotor activity occur shortly before the time of daily food presentation and is called food-anticipatory
MASCO: methamphetaminesensitive circadian oscillator 
FAA: foodanticipatory activity

FEO: foodentrainable oscillator

TTFL: transcriptional/translational feedback loop activity (FAA). FAA appears in SCN-lesioned animals, yet only under a 24-h feeding schedule, demonstrating the existence of an SCNindependent food-entrainable oscillator (FEO) that is not mimicked by a passive hourglass mechanism or by an associated memory process $(161,163)$. The anatomical substrate for the FEO is still unknown. Lesion of candidate areas such as the hypothalamus or limbic system has failed to identify a principal site $(164,165)$, supporting the possibility that the anatomical substrata for the FEO are dispersed in various brain regions or located in peripheral tissues (166). However, recent experiments suggest that the integrity of the dorsomedial hypothalamus $(\mathrm{DMH})$ is important, as lesions in this region can affect behavioral expression of FAA in rats (22; but see also Reference 167). Furthermore, robust oscillations of Per 1 and Per 2 gene expression are seen in the DMH only under restricted feeding conditions (168). Interestingly, Per 2 but not Per1 mutant mice exhibit attenuated food anticipation in mice, as monitored by wheel-running activity, spontaneous locomotor activity, and body temperature (169). Mice with a mutation in the Clock gene show normal FAA (170), but mutation of its analog Npas2 delays FAA in mice (99). Similarly, Cry1/Cry 2 doubleknockout mice display delayed onset and reduced stability of FAA (171). Mice deficient in the Bmal1 gene show robust FAA $(172,173)$. Overall, it appears that FAA does not necessarily require the known clock genes. Blunted FAA in Per 2 mutant animals, containing a Per2 gene with a small in-frame deletion (111), may be due to an effect on FAA that is independent of the function of $P e r 2$ in the circadian clock. This finding may highlight a critical link between the FEO and the RCO in which Per2 may have the role of a synchronizer comparable to its role in linking the activating and inhibiting loops of the core oscillator (174).

Similarities between MASCO and FEO. In a natural setting, animals seek food, and the rewarding properties of food strongly influence food-seeking behavior. Similarly, drug addiction relies on the action of compounds like cocaine or methamphetamine to stimulate brain regions that convey pleasure, which provides motivation and promotes drug-seeking behavior. Food and drug-seeking behavior appear to be linked via hormones, which regulate not only feeding but also neuronal activity in the mesolimbic dopaminergic pathway. In particular, leptin reduces the firing rates of dopaminergic neurons (175), indicating that leptin exerts a direct influence on dopamine neurons via leptin receptors in the VTA (176). Interestingly, leptin-deficient mice show reduced levels of dopamine in the NAc, and leptin treatment increases the synthesis and activity of tyrosine hydroxylase (TH) (176). Mice with a mutation in the Clock gene display elevated leptin levels (177) and TH activity with increased dopamine levels in the VTA (143). Hence, feeding abnormalities and abnormal behavior of Clock mutant mice in mood-related behavioral tests (144) appear to be related. However, it remains to be determined whether the anatomical substrates of the MASCO and FEO are identical or overlap to some degree.

\section{PERIPHERAL CLOCKS}

\section{Circadian Oscillators Are Functional in Most Body Cells}

Shortly after the discovery of the first bona fide clock genes in mammals, it became obvious that circadian clocks are ticking not only in neurons of SCN but also in most, if not all, peripheral tissues $(106,178)$. Moreover, peripheral clocks appear to have a similar molecular makeup as the clocks operative in SCN neurons (179). Thus, in both SCN cells and peripheral cells, the rhythm-generating molecular circuitry is thought to be based on a delayed transcriptional/translational feedback loop (TTFL) involving essentially the same core clock components (see Reference 1). Intriguingly, cultured cells (106) and tissue explants from liver, lung, kidney, spleen, pancreas, heart, stomach, skeletal muscle, lung, cornea, thyroid gland, and adrenal gland exhibit robust circadian oscillations in gene expression (178, 180-182). In 
contrast, analysis of clock gene expression in mouse thymus and testis revealed somewhat conflicting results: One research group could not find cyclic mRNA accumulation, whereas another described a 12-h cycle for clock gene expression (183, 184). Circadian oscillators may not function properly in the immature and differentiating cells that make up a large proportion of these two tissues. For example, embryonic stem cells, which can be regarded as the least-differentiated cells, do not appear to be capable of circadian rhythm generation (E. Kowalska \& S.A. Brown, personal communication).

In peripheral organs a large number of key physiological functions are subject to daily oscillations. These include xenobiotic and endobiotic detoxification by liver, kidney, and small intestine (185); carbohydrate (186) and lipid (187) metabolism by liver, muscle, and adipose tissue; renal plasma flow and urine production; and parameters of the cardiovascular system such as blood pressure and heart beat rates (reviewed in Reference 188). Given the hierarchical architecture of the circadian timing system, these peripheral functions can be coordinated by systemic cues emanating from the SCN, such as neuronal signals and circulating hormones or metabolites, and/or by local peripheral oscillators synchronized by the SCN (for reviews, see References 188-190).

Genome-wide transcriptome profiling studies performed on peripheral tissues such as liver, heart, and adrenal gland suggest that many cellular functions are subject to circadian regulation. Depending on the tissue and on the algorithms used for data mining, between $2 \%$ and $10 \%$ of all detected genes are rhythmically expressed. The liver is the most extensively studied organ in terms of circadian transcription. Independent studies have revealed close to 1000 circadian transcripts in the liver (191-200).

As expected, many of the rhythmically expressed liver genes encode key enzymes involved in metabolic pathways, energy homeostasis, food processing, and detoxification (185). It could be argued that economizing energy expenditure is the major virtue of temporally limited gene expression. However, cells are generally quite wasteful with their fuel resources (see Reference 201 and references therein), and it is thus unlikely that the minor energy savings associated with the temporally gated activity of a few genes is the major purpose of circadian gene expression. Rather, the sequestration of chemically incompatible processes to different time windows and the temporal limitation of potentially harmful processes to time spans during which they are absolutely required may constitute the major tasks of circadian peripheral clocks (see Reference 202 and references therein). For example, a simultaneously high expression of glycogen synthase and glycogen phosphorylase would not be compatible with the conversion of glucose into glycogen and vice versa during the absorptive and postabsorptive phases, respectively. Hence, the antiphasic expression of these two enzymes in liver makes physiological sense (203). Furthermore, cytochrome p450 mono-oxidases, which are involved in xenobiotic detoxification, can produce genotoxic reactive oxygen species from molecular oxygen and thereby cause collateral damage. Therefore, the tight regulation of such enzymes by both hepatocyte oscillators and acute regulatory mechanisms may be meaningful. We thus hypothesize that the anticipation of metabolic pathways to optimize food processing, the limitation of metabolic processes with adverse side effects to time periods when they are needed, and the sequestration of chemically incompatible reactions to different time windows are the three most important purposes of peripheral clocks, at least in metabolically active tissues (reviewed in Reference 202).

Intriguingly, Hogenesch and colleagues (193) have recently demonstrated that, in addition to mRNAs with a 24-h accumulation cycle, two clusters of transcripts cycling with 12-h and 8 -h periods exist in liver. This original discovery further suggests the significance of oscillating gene expression for the temporal separation of metabolic processes.

Studies published during the past few years provide evidence that posttranscriptional mechanisms are also implicated in the fine 
tuning of circadian gene expression. Thus, in liver many proteins issued from constitutively accumulating mRNAs oscillate in abundance, supposedly owing to their rhythmic translation and/or degradation rates (204). Moreover, the hepatocyte-specific microRNA miR122, whose transcription is under the control of the clock component REV-ERB $\alpha$, affects the cyclic expression of numerous regulators and enzymes implicated in lipid and cholesterol metabolism (205).

\section{Properties of Peripheral Oscillators}

It was originally thought that only oscillators in SCN neurons are self-sustained, whereas the peripheral clocks dampen after several cycles. However, Yoo et al. (182) have shown that circadian timekeepers in liver and lung explants can generate up to 20 (or more) daily cycles of Per2luciferase expression. In spite of the resemblance between central and peripheral clocks, the terms of master and slave oscillators are still justified. In fact, the phases of peripheral oscillators exhibit large differences in SCN-lesioned animals. Furthermore, Bittman and colleagues (206) demonstrated that a functional SCN is required to maintain phase coherence between hepatocytes of the same liver. Hence, peripheral oscillators do not appear to be coupled via paracrine communication signals (206). This latter report also suggests that the transplantation of an SCN into SCN-lesioned animals can restore phase coherence of circadian gene expression in liver, kidney, and skeletal muscle, but not in heart, spleen, or adrenal medulla. Perhaps the synchronization of circadian oscillators in the latter three tissues requires inputs from the peripheral nervous system, which probably cannot be restored by an implanted SCN. In a separate study, Bittman and colleagues (207) also performed elegant parabiosis experiments demonstrating that diffusible SCN-derived signals are sufficient for the phase entrainment of liver and kidney.

In 1998 Balsalobre et al. (106) showed that immortalized Rat-1 fibroblasts, which had been propagated in culture for many decades, possess robust circadian oscillators. Since then, circadian gene expression has been observed in a variety of cultured cell lines and primary fibroblasts, including murine NIH-3T3 fibroblasts (208), mouse and human primary fibroblasts (209), and human U2OS osteosarkoma cells (193). The circadian oscillators of such cultured cells can be transiently synchronized by a puzzling variety of signaling pathways involving both transmembrane and nuclear receptors (188). Single-cell recordings and mathematical analysis of bioluminescence cycles generated by cell populations revealed that fibroblasts harbor self-sustained, cell-autonomous oscillators (107, 210) (Figure 4), in keeping with the observations made with peripheral tissue explants (182). The fibroblast clocks exhibit robust but desynchronized oscillations under normal continuous culture conditions. However, as outlined above, these clocks may be transiently synchronized by the activation of several signal transduction pathways.

Peripheral clocks are resilient to large fluctuations in temperature and overall transcription rates. The studies with cultured fibroblasts suggest that, when examined at the single-cell level, peripheral oscillators are at least as robust as those operative in isolated SCN neurons. Thus, oscillators in cultured

Figure 4

Robustness of mammalian cellular clocks. (a) Experimental system for the analysis of circadian gene expression in cell populations or single cells (adapted with permission from References 107 and 215). (b) Temperature fluctuations within the physiological range do not dramatically alter period length. Surprisingly, the cellular circadian oscillators run slightly faster at lower temperatures (temperature overcompensation). (c) During cell division the circadian oscillators keep ticking in daughter cells, and in spite of the sudden division of the cell's contents during this process, the phases undergo only minor advances or delays (adapted from Reference 107). (d) Inhibition of RNA synthesis by $\alpha$-amanitin (an inhibitor of RNA polymerase II-dependent transcription) or actinomycin D (an inhibitor of RNA polymerase I- and II-dependent transcription) does not abolish circadian oscillations. 
a

Fibroblast cell line expressing

bioluminescent circadian reporter

(Bmal1-luciferase, Per2::luciferase, etc.)
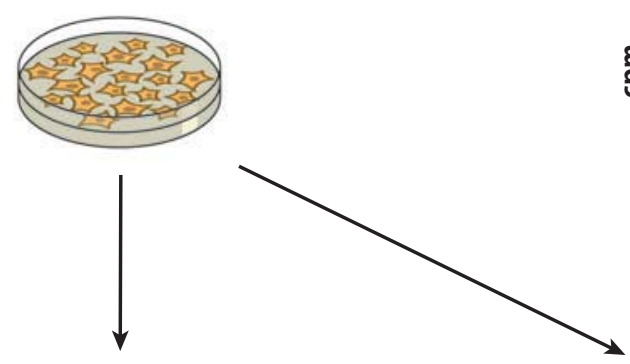

Population circadian bioluminescence analysis

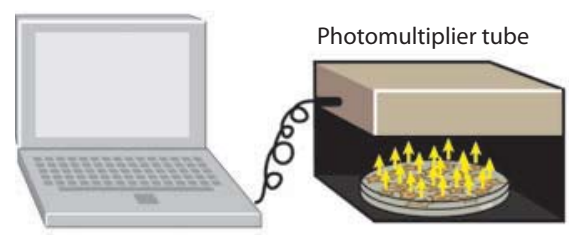

$\frac{1}{0}$
0
0
0
0
0
0

b

C

Cell 1

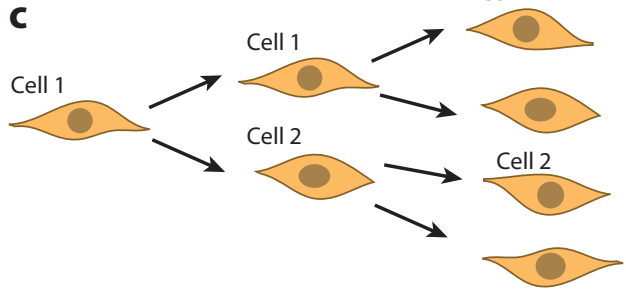

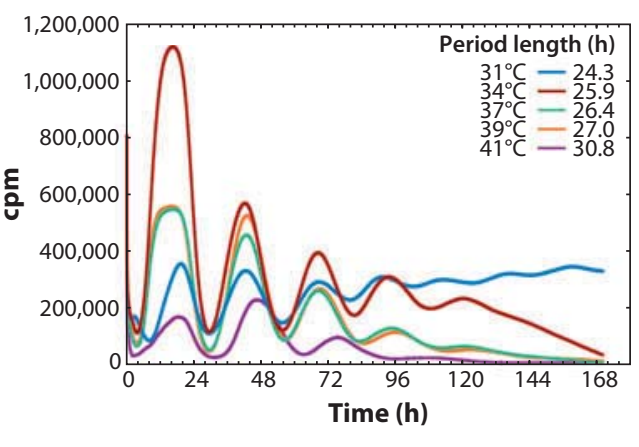

Individual cell oscillation analysis
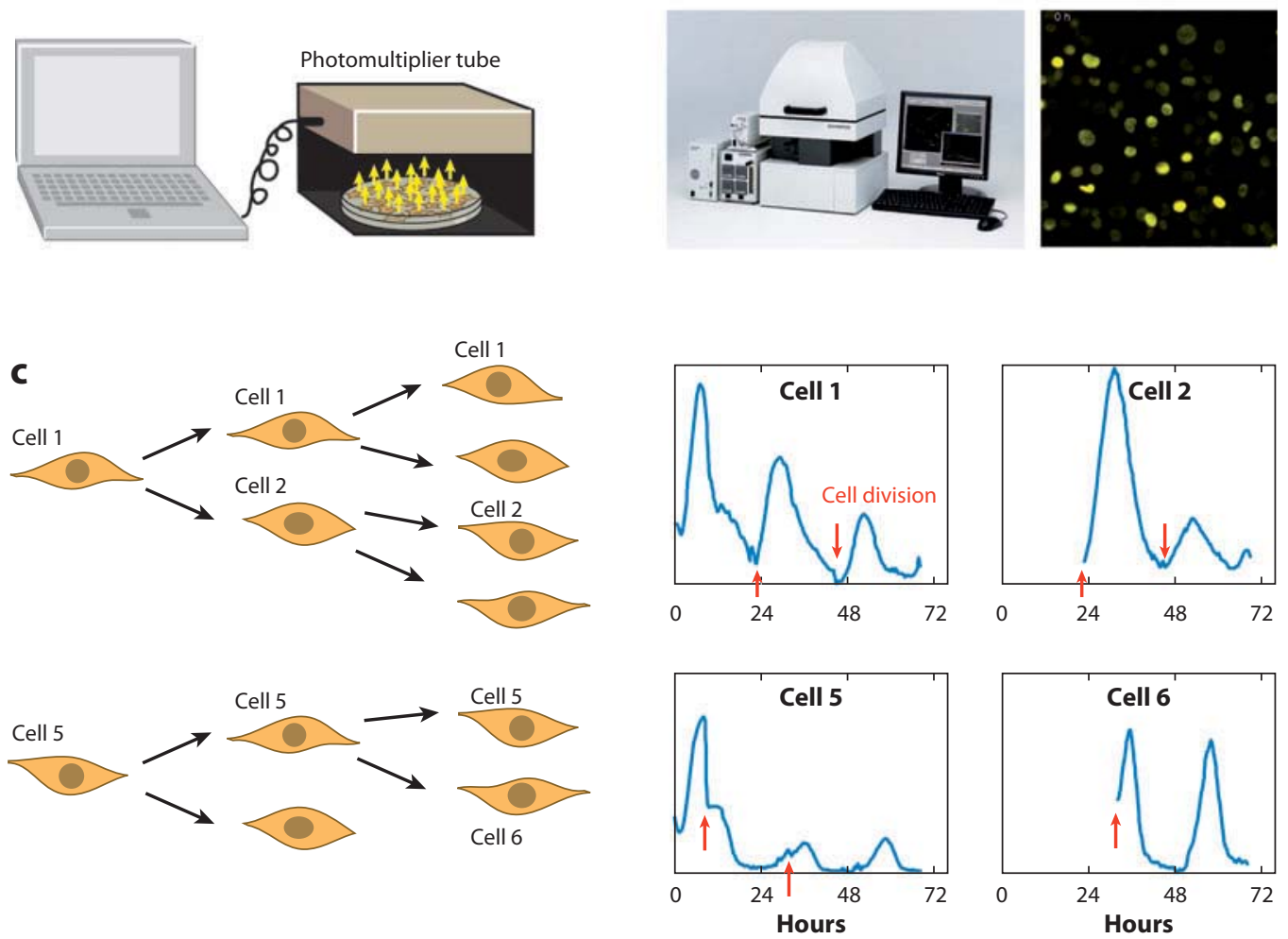

d

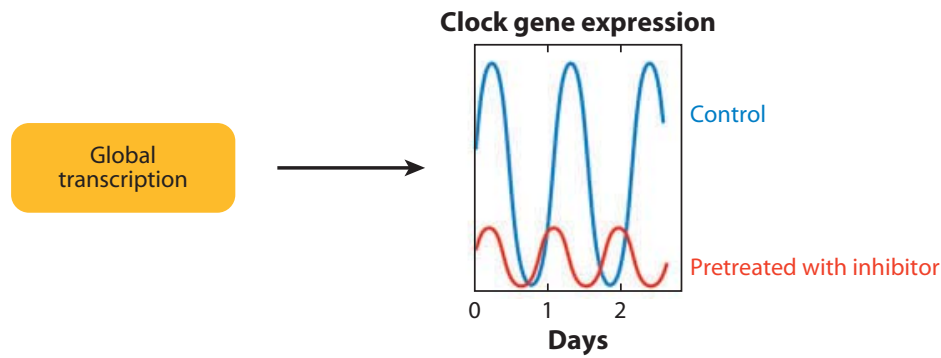


fibroblasts and SCN neurons keep ticking throughout a cell's lifetime. In fibroblasts, circadian gene expression even persists during cell division, and the phase of these oscillations is passed on to daughter cells with only minor advances or delays. Another remarkable aspect of peripheral clock robustness is temperature compensation, a property described several decades ago for many organisms $(211,212)$. In contrast to most chemical and biochemical processes, which are accelerated with increasing temperature, the period length of circadian oscillators remains nearly constant over a wide range of physiological temperatures $(213,214)$. This feature even applies to circadian oscillators operative in cells of homeotherm organisms, such as cultured mammalian fibroblasts. In fact, the oscillators of these cells are even temperature overcompensated, in that they tick slightly faster at lower temperatures (215-217) (Figure 4b). In Drosophila, the Per protein plays a key role in temperature compensation, and $p^{L} r^{L}$ mutant flies lose temperature compensation and exhibit longer periods at higher temperatures (211). We found that Per1-deficient primary mouse tail fibroblasts, in contrast to their wild-type counterparts, are not temperature (over)compensated. Rather, they oscillate with similar and even slightly shorter periods at elevated temperatures. This suggests that PER proteins play an important role in the temperature control of circadian oscillators in mammalian cells as well (215).

Besides being temperature compensated, peripheral clocks also appear to be resilient against fluctuations in oscillator components. As mentioned above, cell division, during which the cellular contents are cut approximately in half, does not abrogate oscillator function but causes only relatively modest phase shifts (Figure 4c) (107). Fibroblast clocks also support large variations in general transcription rates. Thus, circadian oscillator function persists in mouse fibroblasts exposed to sublethal doses of the transcription inhibitors $\alpha$-amanitin and actinomycin D, which lower general RNA polymerase II-dependent transcription by up to threefold (Figure 4d ) (215). Breathtaking work from Kondo and colleagues (218) recently revealed that in cyanobacteria circadian protein phosphorylation can persist in the absence of transcription and translation, at least at certain temperatures. Moreover, this group succeeded in reconstituting a circadian oscillator in the test tube with just three clock proteins (KaiA, KaiB, and KaiC) and ATP (219). However, the same research team recently showed that circadian clock gene transcription is required for fully operative clock function in vivo (220). Hence, the coordinated interaction between posttranslational and transcriptional/translational regulatory mechanisms appears to account for the generation of robust daily rhythms in cyanobacteria. Work on mammalian and insect oscillators resulted in similar conclusions for metazoan systems $(221,222)$, which may explain why absolute cellular concentrations of known clock components do not appear to play preponderant roles in keeping the clocks ticking (see above). The latter notion is also supported by a recent report by Fan and colleagues (223), demonstrating that the overexpression of CRY1, CRY2, and BMAL1, at least within certain limits, does not abrogate oscillator function.

The resilience of cellular clocks to changes in temperature and gene expression may be even more important in peripheral cell types than in the SCN. In contrast to SCN oscillators, whose intercellular communication reinforces their resilience to perturbations (224), peripheral clocks are rather autistic and must thus rely on cell-autonomous robustness. For example, cellular transcription rates can vary dramatically (>20-fold) in different tissues (225). Moreover, even in homeotherm animals like mammals, the ambient temperature can fluctuate significantly between internal organs (e.g., liver, kidney) and tissues exposed to outside temperature (e.g., skin, mucosa, testicles). In addition, fever and hypothermia can lead to large temperature changes, even in internal organs. Because small period-length alterations can result in large phase changes, the robustness of peripheral clocks may be important to assure phase coherence. 
An intriguing area of research concerns the balance between different core clock components necessary for proper clockwork function. The single-cell analysis of fibroblasts from Per1 knockout mice performed by us and others (224) revealed that the low-amplitude oscillations exhibited by these cells at the population level are the result of a small fraction of robustly cycling cells and a large fraction of arrhythmic cells. Therefore, some cells appear to be more sensitive to the absence of PER1 than do other cells, perhaps because PER2 production is upregulated in these cells.

Fibroblast oscillators and behavior. Clock genes are operative in most, if not all, skin cell types and may play a role in several processes such as cellular proliferation (226) and hair follicle cycling (227). Brown and colleagues (209) have compared the wheel-running behavior and the period length of skin fibroblasts of various mice carrying mutations in different core clock genes. Even though the cellular clocks operative in fibroblasts did not perfectly reflect the central clockwork, there was a qualitative correlation between locomotor activity and fibroblast gene expression. Given that the assessment of the circadian period length in human beings is complicated and expensive, the possibility of studying human circadian oscillator properties by using primary fibroblasts was a welcome opportunity. Thus, the skin fibroblast system was also used successfully to characterize amplitude and phase shift properties in individuals with "normal" period lengths but different behavioral phenotypes. These studies suggested that human chronotypes may be influenced not only by the period length of their circadian oscillators but also by cellular components that affect period length, amplitude, and phase (228). Moreover, this system may be exploited for diagnostic purposes, conceivably for subjects with circadian disorders. For example, Vanselow and coworkers (229) have found that a mutation in an mPer 2 phosphoacceptor site corresponding to the $h P E R 2 \mathrm{mu}-$ tation associated with human familial advanced sleep phase syndrome (FASPS) phenocopies the short period and advanced phase in cultured fibroblasts.

\section{Synchronization of Peripheral Clocks}

As mentioned above, the SCN central pacemaker must establish phase coherence in the body by synchronizing billions of individual cell clocks every day $(202,224)$. The SCN uses many routes to establish phase coherence in the periphery. Thus, feeding rhythms, driven by rest-activity rhythms, are strong Zeitgebers for many tissues $(178,230)$. Likewise, body temperature rhythms, influenced directly by the SCN and by activity cycles controlled by the SCN, appear to play a role in the resetting of peripheral timekeepers (231). In addition, the SCN also uses more direct timing cues, such as humoral and neuronal signals, to entrain the phases of peripheral clocks $(87,232)$ (Figure 5). Peripheral clocks continue to oscillate in SCNlesioned mice, but their phases are no longer coordinated in these behaviorally arrhythmic animals $(182,206)$.

Entrainment of peripheral clocks by indirect cues imposed by oscillating behavior: feeding-fasting cycles and temperature. Daily feeding-fasting cycles appear to be the dominant Zeitgebers for several peripheral organs, including liver, kidney, pancreas, and heart. The timing of food intake influences the expression profile of many circadian genes in these organs. Normally, the feeding-fasting cycles are in phase with rest-activity cycles. Strikingly, daytime-restricted feeding of nocturnal rodents inverts the phase of gene expression in peripheral organs, thereby uncoupling peripheral clocks from the SCN (230, 233). The entrainment pathways from feedingfasting cycles may include hormones secreted upon feeding and fasting [for example, cholecystokinin, peptide YY, oxyntomodulin, ghrelin, leptin (234)], food metabolites (for example, glucose, cholesterol, fatty acids, heme), postprandial temperature elevations, and intracellular redox state $\left[\mathrm{NAD}(\mathrm{P}) \mathrm{H} / \mathrm{NAD}(\mathrm{P})^{+}\right.$ratio $(235$ and references therein)]. 


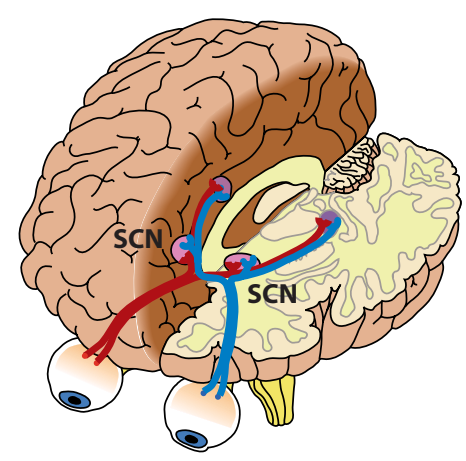

$\mathrm{SCN}$

(central clock)
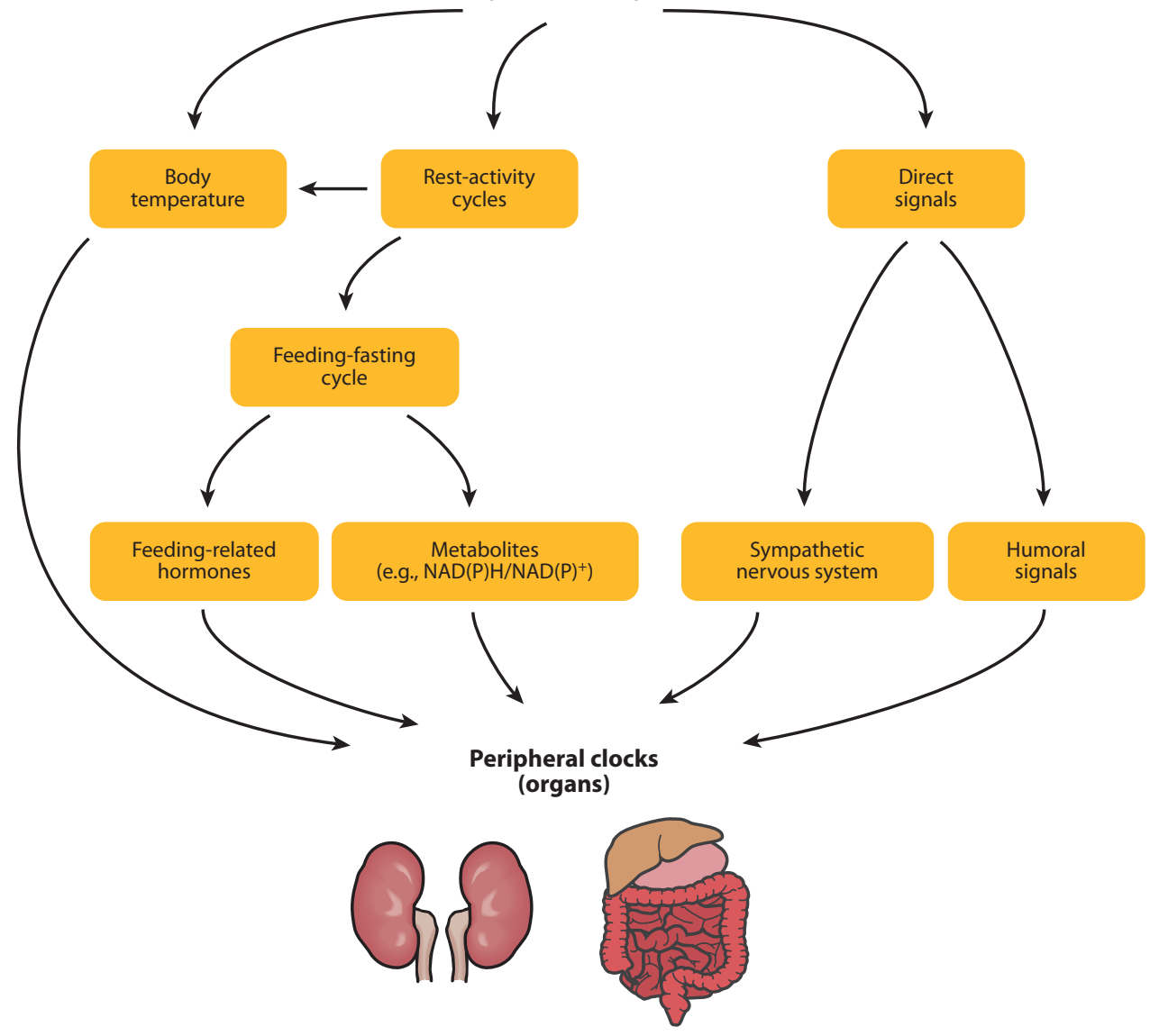

Figure 5

Peripheral clock entrainment pathways (see text for explanations).

There is growing evidence for the interplay between energy metabolism and the circadian clock (236-238). First, the dominance of feeding cycles as a Zeitgeber for peripheral clocks implies that the circadian timing system plays an important role in nutrient processing and energy homeostasis. In addition, as we mentioned above, transcriptome profiling 
studies revealed that many genes involved in metabolism are rhythmically expressed (191, 192, 194, 199, 239, 240). Furthermore, at least in vitro, the DNA-binding activity of BMAL1CLOCK is strongly influenced by the ratio of reduced to oxidized NAD cofactors, which are often considered to be readouts of the cellular metabolic state (241).

Mammalian SIRT1, an $\mathrm{NAD}^{+}$-dependent deacetylase, has been recently identified as a novel regulator of circadian gene expression (242, 243). SIRT1, the mammalian ortholog of yeast Sir2, is involved in transcriptional silencing, genome stability, and longevity (244, 245). Asher and colleagues (242) demonstrated that SIRT1 exhibits circadian accumulation in mouse hepatocytes and cultured fibroblasts and that it is essential for high-magnitude circadian transcription of several core clock genes, including Bmal1, Ror $\alpha$, Per2, and Cry1. Moreover, SIRT1 binds CLOCK-BMAL1 in a circadian manner and promotes the deacetylation and subsequent degradation of PER2 (242).

Temperature fluctuations represent an important entrainment cue in Drosopbila, Neurospora, and mammals (246 and references therein). Shallow temperature rhythms imitating body temperature fluctuations can maintain previously induced rhythms in peripheral oscillators, and can phase shift peripheral clocks, without affecting the phase of SCN (231). In zebrafish kept in constant darkness, temperature steps of as little as $2^{\circ} \mathrm{C}$ can entrain circadian rhythms in developing larvae (and in zebrafish cell lines) (247).

Using a novel screen dubbed differential display of DNA-binding proteins (DDDP) of mouse liver nuclear extracts, Reinke and coworkers (248) have found a highly rhythmic activity of heat-shock factor 1 (HSF1). HSF1 drives the expression of heat-shock proteins at the onset of the dark phase, when the animals start to be behaviorally active. The onset of feeding is followed by a postprandial rise in body temperature, which makes it difficult to discriminate between temperature-dependent and chemical HSF1 activation pathways. Nevertheless, recent studies with cultured cells indicate that HSF1 not only governs part of the cytoprotection system but also plays a role in the synchronization of peripheral cells (C. Saini \& U. Schibler, unpublished results).

Entrainment by hormonal and neuronal signals emanating from the SCN. The SCN also employs more direct signals, such as neural and humoral outputs, to synchronize peripheral clocks.

Plasma glucocorticoid hormone levels exhibit robust daily oscillations in both laboratory rodents and humans, and these cycles are driven by SCN via the hypothalamic-Pitadrenal axis (249). Interestingly, the glucocorticoid nuclear hormone receptor is expressed in virtually all cell types, except in SCN neurons (see Reference 250 and references therein). In keeping with this expression pattern, dexamethasone, a glucocorticoid receptor agonist, acts as a strong Zeitgeber in vivo. Dexamethasone synchronizes rat-1 fibroblasts and causes phase shifts in peripheral oscillators but does not affect SCN rhythms (250). Thus, glucocorticoid hormones possess clock-resetting properties and represent an important phaseentrainment signal from the SCN. Due to the redundancy of synchronization pathways, the steady-state phase can be established in the absence of glucocorticoid receptors in peripheral tissues such as the liver. Nonetheless, the involvement of glucocorticoid signaling can be demonstrated by determining the kinetics of feeding-induced phase inversion. Thus, hepatocytes devoid of a functional glucocorticoid receptor gene adapt the phase much more rapidly to daytime feeding than do wild-type hepatocytes (251).

The autonomic nervous system constitutes an additional direct synchronization pathway employed by the SCN. For example, by surgically disrupting liver innervation, Buijs and coworkers (87) demonstrated that light may affect liver gene expression not only via the hormonal pathway but also via autonomic input. Hence, the autonomic nervous system may play a role in the resetting of peripheral clocks after phase shift-inducing light
DDDP: differential

display of DNA-

binding proteins

HSF1: heat-shock factor 1 
exposure (87). In addition, the same group has found that plasma glucose and insulin concentrations are affected by administering glutamatergic agonists or GABAergic antagonists. The hyperglycemic effect of the GABA antagonist is absent in SCN-ablated animals. The control of daily glucose metabolism in the liver indicates an important role for GABAergic/ glutamatergic SCN inputs to the hypothalamic preautonomic neurons that are connected to the liver (252). Furthermore, an elegant study by Okamura and colleagues (86) revealed that adrenal innervation is required for lightinduced corticosterone secretion by the adrenal gland, thus representing a direct output from the SCN to the adrenal cortex.

Under certain circumstances, different timing cues can be in conflict with each other. We mention above that food availability during the inactivity phase will override more direct SCN-driven phase-resetting signals in the liver (194, 251). By contrast, in the submaxillary salivary gland, temporal food restriction fails to entrain circadian gene expression. However, upon sympathetic denervation, the submaxillary gland oscillators rapidly adjust their phase to the inverted feeding regimen. This finding further suggests that sympathetic inputs are important for the phase entrainment of peripheral oscillators and that multiple synchronization pathways can contribute to peripheral oscillator synchronization in the same tissue (232).

\section{A Few Selected Outputs of Peripheral Oscillators}

Hepatic clocks in glucose and lipid metabolism. Rhythmically expressed liver genes are implicated in the metabolism of fatty acids, cholesterol, bile acids, amino acids, and xenobiotics $(185,196,199,239)$. The disruption of circadian oscillator function causes alterations in metabolism (reviewed in Reference 253). For instance, mutations in the essential clock genes Bmal1 and Clock lead to various metabolic disorders (254). Elegant work by Weitz and colleagues (186) suggests that functional liver clocks contribute to glucose homeostasis by driving a daily rhythm of hepatic glucose export. Using the Cre-loxP recombination strategy in mice, these authors inactivated Bmal1 either in all cells $\left(\right.$ Bmal1 $\left.^{-/-}\right)$or specifically in hepatocytes (L-Bmal1 ${ }^{-/-}$). Their experiments suggest that BMAL1 function is important for the regulation of total body fat, glucose clearance, and insulin production. Animals with a liver-specific Bmal1 disruption suffer from hypoglycemia during the inactivity phase. Yet, mice deficient in BMAL1 in all cells do not show overt problems with their resting blood sugar levels. Hence, in L-Bmal1 ${ }^{-/-}$mice, the lack of liver rhythms-rather than just the lack of the BMAL1 transcription factor-must be the cause of impaired glucose homeostasis. Of note, Weitz and colleagues (186) have described a similar pattern of metabolic defects in $P e r 1^{-/-}, P e r 2^{-/-}$double-mutant mice, which also have a disrupted clock. Moreover, a genetic linkage analysis in humans has recently shown that $b P E R 2$ activity may be associated with blood glucose levels as well (255).

Recent studies by Le Martelot and colleagues (187) further underscore the tight link between the circadian clock and metabolism in the liver. These authors have demonstrated an important role for $R E V-E R B \alpha$ in the circadian regulation of cholesterol and bile acid synthesis (187). Genetic loss- and gain-of-function experiments suggest that $R E V-E R B \alpha$ participates in the circadian modulation of sterol regulatory element-binding protein (SREBP) activity and thereby in the daily expression of SREBP target genes involved in cholesterol and lipid metabolism (187). This regulation is accomplished via the cyclic transcription of Insig2, which encodes a transmembrane protein that sequesters SREBPs to the endoplasmic reticulum (ER) membranes and thereby interferes with the proteolytic activation of SREBPs in Golgi membranes. Probably through this mechanism, $R E V-E R B \alpha$ also participates in the regulation of cyclic cholesterol-7 $\alpha$-hydroxylase (Cyp7a1) expression. Thus, the authors of this report speculate that the SREBP-dependent production of cholesterol is accompanied by the generation of oxysterols, which in turn activate 
the nuclear receptor LXR and hence the LXR target gene Cyp7a1.

Pancreas clocks, melatonin signaling, and diabetes. An additional connection between circadian oscillators and glucose homeostasis has emerged from recent studies on melatonin receptors in the pancreas (256). Melatonin is a circulating neurohormone that is secreted predominantly by the pineal gland at night. The hormone regulates circadian rhythms by assisting the translation of photoperiodic information in the brain. Melatonin signaling is mainly mediated by two receptors, MT1 and MT2, encoded by the MTNR1A and MTNR1B genes, respectively. The strongest MT2 expression levels are detected in the retina and in the SCN. MT2-mediated melatonin signaling may indirectly regulate glucose level and insulin secretion through the SCN (257). In healthy individuals insulin secretion follows a circadian rhythm. This rhythm, generated within the islets, may be induced by melatonin, which provokes a phase shift in insulin secretion (256). Indeed, $M T N R 1 A$ is highly expressed in pancreatic islets and is, in general, more abundant than MTNR1B. The presence of MTNR1B was recently confirmed in both pancreatic islets and sorted $\beta$-cells, suggesting a possible direct role of MT2 in the regulation of insulin secretion (258). Genetic studies in humans have revealed a possible link between $M T N R 1 B$ allele variants and hyperglycemia, impaired earlyphase insulin secretion, and $\beta$-cell function (258, 259). Thus, MTNR1B, expressed in human pancreatic $\beta$-cells, may represent an important connection between circadian clocks and glucose homeostasis, and its detailed analysis may open new avenues for the treatment of type 2 diabetes. Recent studies on transgenic mice underscore the involvement of melatonin signaling in islet function. Analysis of circadian gene expression in pancreas (and liver) of melatonin receptor knockout mice revealed changes in both phase and amplitude. Moreover, an upregulation of insulin secretion was detected in isolated islets of MT1 and MT2 single-knockout mice and MT1/MT2 double-knockout animals, confirming the negative action of melatonin signaling on insulin secretion (260).

\section{CONCLUSIONS AND PERSPECTIVES}

Remarkable progress has been made in our understanding of the mammalian circadian timing system during the past few years. The molecular oscillator model has been considerably revised and amended. In particular, a plethora of posttranslational regulatory mechanisms have been shown to contribute critically to proper clock function in addition to the canonical TTFL. Furthermore, the evidence for a tight coupling of circadian gene expression to metabolic cycles in mammalian cells, originally proposed by Rutter and colleagues (241), is now stronger. A new level of complexity has recently been added to the mammalian circadian timing system by findings that microRNAs participate in the control of posttranscriptional clock output pathways $(205,261)$. However, we must consider that core clock proteins also perform noncircadian functions. That is, when we study organisms with mutations in core clock genes, we must discriminate between clock gene phenotypes and clock phenotypes. For example, the deficiencies of clock mutant mice in bone formation, tumor surveillance, and metabolic pathways may have no causal relationship with the circadian clock. Indeed, the rigorous discrimination between clock function and clock gene function is not a trivial matter and to date has been accomplished in only a few isolated cases by so-called resonance studies (262-264). Now that period-length mutations are available for laboratory mice (265 and references therein), such studies could be performed for mammalian organisms. Even in the absence of such evidence, the facts remain that hundreds of genes are expressed in a cyclic manner and that most physiology follows a daily rhythm. Alas, this knowledge is largely ignored in the clinic, and only a few pioneers are making efforts to explore this temporal information in designing better therapies (266). 
The synchronization pathways of peripheral clocks by the SCN remain largely unknown. Many signaling pathways are expected to participate in the phase entrainment of peripheral clocks. Hence, the elimination of a single pathway is unlikely to significantly affect the steady-state phase of circadian clocks. A more sensitive approach would be the recording of phase-shifting kinetics. Ideally, such recording would be performed at a high temporal resolution in living animals. It will thus be of utmost importance to develop novel noninvasive whole-body imaging techniques allowing the recording of central and peripheral gene expression patterns in freely moving animals.

\section{SUMMARY POINTS}

1. The main circadian oscillator in the brain is located in the suprachiasmatic nuclei (SCN). Secondary oscillators exist in the brain.

2. Light adjusts the phase of the SCN oscillator to the environmental light-dark cycle.

3. Neural and humoral signals from the SCN can synchronize central and peripheral oscillators and vice versa.

4. In the periphery, circadian clocks are functional in most body cells.

5. Peripheral oscillators are self-sustained; cell-autonomous; and resilient to cell division, to acute stress, and to fluctuations in temperature and general transcription rate.

6. The combination of environmental inputs—such as daily fasting-feeding cycles, temperature cycles, the cellular redox state, and direct neural and humoral signals from the $\mathrm{SCN}$-represents essential entrainment cues for the peripheral clocks.

\section{DISCLOSURE STATEMENT}

The authors are not aware of any affiliations, memberships, funding, or financial holdings that might be perceived as affecting the objectivity of this review.

\section{LITERATURE CITED}

1. Welsh DK, Takahashi JS, Kay SA. 2010. Suprachiasmatic nucleus: cell autonomy and network properties. Annu. Rev. Physiol. 72:551-77

2. Pittendrigh CS. 1960. Circadian rhythms and the circadian organization of living systems. Cold Spring Harbor Symp. Quant. Biol. 25:159-84

3. Moore RY, Eichler VB. 1972. Loss of a circadian adrenal corticosterone rhythm following suprachiasmatic lesions in the rat. Brain Res. 42:201-6

4. Stephan FK, Zucker I. 1972. Circadian rhythms in drinking behavior and locomotor activity of rats are eliminated by hypothalamic lesions. Proc. Natl. Acad. Sci. USA 69:1583-86

5. Lehman MN, Silver R, Gladstone WR, Kahn RM, Gibson M, Bittman EL. 1987. Circadian rhythmicity restored by neural transplant. Immunocytochemical characterization of the graft and its integration with the host brain. 7. Neurosci. 7:1626-38

6. Ralph MR, Foster RG, Davis FC, Menaker M. 1990. Transplanted suprachiasmatic nucleus determines circadian period. Science 247:975-78

7. Sujino M, Masumoto KH, Yamaguchi S, van der Horst GT, Okamura H, Inouye ST. 2003. Suprachiasmatic nucleus grafts restore circadian behavioral rhythms of genetically arrhythmic mice. Curr. Biol. 13:664-68 
8. Inouye ST, Kawamura H. 1979. Persistence of circadian rhythmicity in a mammalian hypothalamic "island" containing the suprachiasmatic nucleus. Proc. Natl. Acad. Sci. USA 76:5962-66

9. Green DJ, Gillette R. 1982. Circadian rhythm of firing rate recorded from single cells in the rat suprachiasmatic brain slice. Brain Res. 245:198-200

10. Groos G, Hendriks J. 1982. Circadian rhythms in electrical discharge of rat suprachiasmatic neurones recorded in vitro. Neurosci. Lett. 34:283-88

11. Shibata S, Oomura Y, Kita H, Hattori K. 1982. Circadian rhythmic changes of neuronal activity in the suprachiasmatic nucleus of the rat hypothalamic slice. Brain Res. 247:154-58

12. Bos NP, Mirmiran M. 1990. Circadian rhythms in spontaneous neuronal discharges of the cultured suprachiasmatic nucleus. Brain Res. 511:158-62

13. Welsh DK, Logothetis DE, Meister M, Reppert SM. 1995. Individual neurons dissociated from rat suprachiasmatic nucleus express independently phased circadian firing rhythms. Neuron 14:697-706

14. Schwartz WJ, Gainer H. 1977. Suprachiasmatic nucleus: use of 14C-labeled deoxyglucose uptake as a functional marker. Science 197:1089-91

15. Sun ZS, Albrecht U, Zhuchenko O, Bailey J, Eichele G, Lee CC. 1997. RIGUI, a putative mammalian ortholog of the Drosophila period gene. Cell 90:1003-11

16. Tei H, Okamura H, Shigeyoshi Y, Fukuhara C, Ozawa R, et al. 1997. Circadian oscillation of a mammalian homologue of the Drosophila period gene. Nature 389:512-16

17. Hastings MH, Field MD, Maywood ES, Weaver DR, Reppert SM. 1999. Differential regulation of mPER1 and mTIM proteins in the mouse suprachiasmatic nuclei: new insights into a core clock mechanism. F. Neurosci. 19:RC11

18. Langner R, Rensing L. 1972. Circadian rhythm of oxygen consumption in rat liver suspension culture: changes of pattern. Z. Naturforsch. Teil B 27:1117-18

19. Berson DM, Dunn FA, Takao M. 2002. Phototransduction by retinal ganglion cells that set the circadian clock. Science 295:1070-73

20. Moore RY, Speh JC, Card JP. 1995. The retinohypothalamic tract originates from a distinct subset of retinal ganglion cells. F. Comp. Neurol. 352:351-66

21. Provencio I, Jiang G, De Grip WJ, Hayes WP, Rollag MD. 1998. Melanopsin: an opsin in melanophores, brain, and eye. Proc. Natl. Acad. Sci. USA 95:340-45

22. Gooley JJ, Lu J, Chou TC, Scammell TE, Saper CB. 2001. Melanopsin in cells of origin of the retinohypothalamic tract. Nat. Neurosci. 4:1165

23. Hattar S, Liao HW, Takao M, Berson DM, Yau KW. 2002. Melanopsin-containing retinal ganglion cells: architecture, projections, and intrinsic photosensitivity. Science 295:1065-70

24. Provencio I, Rodriguez IR, Jiang G, Hayes WP, Moreira EF, Rollag MD. 2000. A novel human opsin in the inner retina. F. Neurosci. 20:600-5

25. Moore RY, Lenn NJ. 1972. A retinohypothalamic projection in the rat. F. Comp. Neurol. 146:1-14

26. Ibata Y, Takahashi Y, Okamura H, Kawakami F, Terubayashi H, et al. 1989. Vasoactive intestinal peptide (VIP)-like immunoreactive neurons located in the rat suprachiasmatic nucleus receive a direct retinal projection. Neurosci. Lett. 97:1-5

27. Tanaka M, Ichitani Y, Okamura H, Tanaka Y, Ibata Y. 1993. The direct retinal projection to VIP neuronal elements in the rat SCN. Brain Res. Bull. 31:637-40

28. Castel M, Belenky M, Cohen S, Ottersen OP, Storm-Mathisen J. 1993. Glutamate-like immunoreactivity in retinal terminals of the mouse suprachiasmatic nucleus. Eur. F. Neurosci. 5:368-81

29. Hannibal J, Ding JM, Chen D, Fahrenkrug J, Larsen PJ, et al. 1997. Pituitary adenylate cyclase-activating peptide (PACAP) in the retinohypothalamic tract: a potential daytime regulator of the biological clock. 7. Neurosci. 17:2637-44

30. Hirota T, Fukada Y. 2004. Resetting mechanism of central and peripheral circadian clocks in mammals. Zool. Sci. 21:359-68

31. Crosio C, Cermakian N, Allis CD, Sassone-Corsi P. 2000. Light induces chromatin modification in cells of the mammalian circadian clock. Nat. Neurosci. 3:1241-47

32. Albrecht U, Sun ZS, Eichele G, Lee CC. 1997. A differential response of two putative mammalian circadian regulators, mper 1 and mper 2 , to light. Cell 91:1055-64 
33. Shearman LP, Zylka MJ, Weaver DR, Kolakowski LF Jr, Reppert SM. 1997. Two period homologs: circadian expression and photic regulation in the suprachiasmatic nuclei. Neuron 19:1261-69

34. Shigeyoshi Y, Taguchi K, Yamamoto S, Takekida S, Yan L, et al. 1997. Light-induced resetting of a mammalian circadian clock is associated with rapid induction of the mPer1 transcript. Cell 91:1043-53

35. Morris ME, Viswanathan N, Kuhlman S, Davis FC, Weitz CJ. 1998. A screen for genes induced in the suprachiasmatic nucleus by light. Science 279:1544-47

36. Hamada T, Liou SY, Fukushima T, Maruyama T, Watanabe S, et al. 1999. The role of inositol trisphosphate-induced $\mathrm{Ca}^{2+}$ release from $\mathrm{IP}_{3}$-receptor in the rat suprachiasmatic nucleus on circadian entrainment mechanism. Neurosci. Lett. 263:125-28

37. Ding JM, Buchanan GF, Tischkau SA, Chen D, Kuriashkina L, et al. 1998. A neuronal ryanodine receptor mediates light-induced phase delays of the circadian clock. Nature 394:381-84

38. Pfeffer M, Müller CM, Mordel J, Meissl H, Ansari N, et al. 2009. The mammalian molecular clockwork controls rhythmic expression of its own input pathway components. F. Neurosci. 29:6114-23

39. Duffield GE, Watson NP, Mantani A, Peirson SN, Robles-Murguia M, et al. 2009. A role for Id2 in regulating photic entrainment of the mammalian circadian system. Curr. Biol. 19:297-304

40. Coogan AN, Piggins HD. 2003. Circadian and photic regulation of phosphorylation of ERK1/2 and Elk-1 in the suprachiasmatic nuclei of the Syrian hamster. F. Neurosci. 23:3085-93

41. Kornhauser JM, Mayo KE, Takahashi JS. 1996. Light, immediate-early genes, and circadian rhythms. Bebav. Genet. 26:221-40

42. Obrietan K, Impey S, Storm DR. 1998. Light and circadian rhythmicity regulate MAP kinase activation in the suprachiasmatic nuclei. Nat. Neurosci. 1:693-700

43. Grewal SS, York RD, Stork PJ. 1999. Extracellular-signal-regulated kinase signalling in neurons. Curn Opin. Neurobiol. 9:544-53

44. Motzkus D, Maronde E, Grunenberg U, Lee CC, Forssmann W, Albrecht U. 2000. The human PER1 gene is transcriptionally regulated by multiple signaling pathways. FEBS Lett. 486:315-19

45. Travnickova-Bendova Z, Cermakian N, Reppert SM, Sassone-Corsi P. 2002. Bimodal regulation of mPeriod promoters by CREB-dependent signaling and CLOCK/BMAL1 activity. Proc. Natl. Acad. Sci. USA 99:7728-33

46. Akiyama M, Kouzu Y, Takahashi S, Wakamatsu H, Moriya T, et al. 1999. Inhibition of light- or glutamateinduced mPer1 expression represses the phase shifts into the mouse circadian locomotor and suprachiasmatic firing rhythms. $\mathcal{F}$. Neurosci. 19:1115-21

47. Tischkau SA, Mitchell JW, Tyan SH, Buchanan GF, Gillette MU. 2003. Ca ${ }^{2+} / \mathrm{cAMP}$ response elementbinding protein (CREB)-dependent activation of Per1 is required for light-induced signaling in the suprachiasmatic nucleus circadian clock. F. Biol. Chem. 278:718-23

48. Wakamatsu H, Takahashi S, Moriya T, Inouye ST, Okamura H, et al. 2001. Additive effect of mPer1 and mPer2 antisense oligonucleotides on light-induced phase shift. NeuroReport 12:127-31

49. Albrecht U, Zheng B, Larkin D, Sun ZS, Lee CC. 2001. MPer1 and mper2 are essential for normal resetting of the circadian clock. F. Biol. Rhythms 16:100-4

50. Spoelstra K, Albrecht U, van der Horst GT, Brauer V, Daan S. 2004. Phase responses to light pulses in mice lacking functional per or cry genes. F. Biol. Rhythms 19:518-29

51. Spoelstra K, Daan S. 2008. Effects of constant light on circadian rhythmicity in mice lacking functional cry genes: dissimilar from per mutants. F. Comp. Physiol. A 194:235-42

52. Moore RY, Card JP. 1994. Intergeniculate leaflet: an anatomically and functionally distinct subdivision of the lateral geniculate complex. F. Comp. Neurol. 344:403-30

53. Pickard GE. 1985. Bifurcating axons of retinal ganglion cells terminate in the hypothalamic suprachiasmatic nucleus and the intergeniculate leaflet of the thalamus. Neurosci. Lett. 55:211-17

54. Harrington ME, Nance DM, Rusak B. 1985. Neuropeptide Y immunoreactivity in the hamster geniculosuprachiasmatic tract. Brain Res. Bull. 15:465-72

55. Freeman DA, Dhandapani KM, Goldman BD. 2004. The thalamic intergeniculate leaflet modulates photoperiod responsiveness in Siberian hamsters. Brain Res. 1028:31-38

56. Kim HJ, Harrington ME. 2008. Neuropeptide Y-deficient mice show altered circadian response to simulated natural photoperiod. Brain Res. 1246:96-100 
57. Meyer-Bernstein EL, Morin LP. 1996. Differential serotonergic innervation of the suprachiasmatic nucleus and the intergeniculate leaflet and its role in circadian rhythm modulation. F. Neurosci. 16:2097111

58. Leander P, Vrang N, Møller M. 1998. Neuronal projections from the mesencephalic raphe nuclear complex to the suprachiasmatic nucleus and the deep pineal gland of the golden hamster (Mesocricetus auratus). 7. Comp. Neurol. 399:73-93

59. Moga MM, Moore RY. 1997. Organization of neural inputs to the suprachiasmatic nucleus in the rat. 7. Comp. Neurol. 389:508-34

60. Bosler O, Beaudet A. 1985. VIP neurons as prime synaptic targets for serotonin afferents in rat suprachiasmatic nucleus: a combined radioautographic and immunocytochemical study. F. Neurocytol. 14:749-63

61. Kiss J, Leranth C, Halasz B. 1984. Serotoninergic endings on VIP-neurons in the suprachiasmatic nucleus and on ACTH-neurons in the arcuate nucleus of the rat hypothalamus. A combination of high resolution autoradiography and electron microscopic immunocytochemistry. Neurosci. Lett. 44:119-24

62. van den Pol AN, Tsujimoto KL. 1985. Neurotransmitters of the hypothalamic suprachiasmatic nucleus: immunocytochemical analysis of 25 neuronal antigens. Neuroscience 15:1049-86

63. van Esseveldt KE, Lehman MN, Boer GJ. 2000. The suprachiasmatic nucleus and the circadian timekeeping system revisited. Brain Res. Brain Res. Rev. 33:34-77

64. Watts AG, Swanson LW. 1987. Efferent projections of the suprachiasmatic nucleus. II. Studies using retrograde transport of fluorescent dyes and simultaneous peptide immunohistochemistry in the rat. 7. Comp. Neurol. 258:230-52

65. Morin LP, Goodless-Sanchez N, Smale L, Moore RY. 1994. Projections of the suprachiasmatic nuclei, subparaventricular zone and retrochiasmatic area in the golden hamster. Neuroscience 61:391-410

66. Morin LP. 2007. SCN organization reconsidered. F. Biol. Rhythms 22:3-13

67. Morin LP, Allen CN. 2006. The circadian visual system, 2005. Brain Res. Rev. 51:1-60

68. Buijs RM, Wortel J, Hou YX. 1995. Colocalization of $\gamma$-aminobutyric acid with vasopressin, vasoactive intestinal peptide, and somatostatin in the rat suprachiasmatic nucleus. 7. Comp. Neurol. 358:343-52

69. Castel M, Morris JF. 2000. Morphological heterogeneity of the GABAergic network in the suprachiasmatic nucleus, the brain's circadian pacemaker. F. Anat. 196(Pt. 1):1-13

70. Hermes ML, Coderre EM, Buijs RM, Renaud LP. 1996. GABA and glutamate mediate rapid neurotransmission from suprachiasmatic nucleus to hypothalamic paraventricular nucleus in rat. F. Physiol. 496(Pt. 3):749-57

71. Kalsbeek A, van Heerikhuize JJ, Wortel J, Buijs RM. 1996. A diurnal rhythm of stimulatory input to the hypothalamo-pituitary-adrenal system as revealed by timed intrahypothalamic administration of the vasopressin V1 antagonist. 7. Neurosci. 16:5555-65

72. Kalsbeek A, Buijs RM, van Heerikhuize JJ, Arts M, van der Woude TP. 1992. Vasopressin-containing neurons of the suprachiasmatic nuclei inhibit corticosterone release. Brain Res. 580:62-67

73. Kraves S, Weitz CJ. 2006. A role for cardiotrophin-like cytokine in the circadian control of mammalian locomotor activity. Nat. Neurosci. 9:212-19

74. Cheng MY, Bullock CM, Li C, Lee AG, BermakJC, et al. 2002. Prokineticin 2 transmits the behavioural circadian rhythm of the suprachiasmatic nucleus. Nature 417:405-10

75. Kalsbeek A, Buijs RM. 1992. Peptidergic transmitters of the suprachiasmatic nuclei and the control of circadian rhythmicity. Prog. Brain Res. 92:321-33

76. Kramer A, Yang FC, Snodgrass P, Li X, Scammell TE, et al. 2001. Regulation of daily locomotor activity and sleep by hypothalamic EGF receptor signaling. Science 294:2511-15

77. Li X, Sankrithi N, Davis FC. 2002. Transforming growth factor- $\alpha$ is expressed in astrocytes of the suprachiasmatic nucleus in hamster: role of glial cells in circadian clocks. NeuroReport 13:2143-47

78. Cheng MY, Bittman EL, Hattar S, Zhou QY. 2005. Regulation of prokineticin 2 expression by light and the circadian clock. BMC Neurosci. 6:17

79. Cheng MY, Leslie FM, Zhou QY. 2006. Expression of prokineticins and their receptors in the adult mouse brain. f. Comp. Neurol. 498:796-809

80. Li JD, Hu WP, Boehmer L, Cheng MY, Lee AG, et al. 2006. Attenuated circadian rhythms in mice lacking the prokineticin 2 gene. $\mathcal{F}$. Neurosci. 26:11615-23 
81. Prosser HM, Bradley A, Chesham JE, Ebling FJ, Hastings MH, Maywood ES. 2007. Prokineticin receptor 2 (Prokr2) is essential for the regulation of circadian behavior by the suprachiasmatic nuclei. Proc. Natl. Acad. Sci. USA 104:648-53

82. Silver R, LeSauter J, Tresco PA, Lehman MN. 1996. A diffusible coupling signal from the transplanted suprachiasmatic nucleus controlling circadian locomotor rhythms. Nature 382:810-13

83. Meyer-Bernstein EL, Morin LP. 1999. Electrical stimulation of the median or dorsal raphe nuclei reduces light-induced FOS protein in the suprachiasmatic nucleus and causes circadian activity rhythm phase shifts. Neuroscience 92:267-79

84. Buijs RM, Wortel J, Van Heerikhuize JJ, Feenstra MG, Ter Horst GJ, et al. 1999. Anatomical and functional demonstration of a multisynaptic suprachiasmatic nucleus adrenal (cortex) pathway. Eur: 7 . Neurosci. 11:1535-44

85. Kaneko M, Hiroshige T, Shinsako J, Dallman MF. 1980. Diurnal changes in amplification of hormone rhythms in the adrenocortical system. Am. F. Physiol. 239:R309-16

86. Ishida A, Mutoh T, Ueyama T, Bando H, Masubuchi S, et al. 2005. Light activates the adrenal gland: timing of gene expression and glucocorticoid release. Cell Metab. 2:297-307

87. Cailotto C, Lei J, van der Vliet J, van Heijningen C, van Eden CG, et al. 2009. Effects of nocturnal light on (clock) gene expression in peripheral organs: a role for the autonomic innervation of the liver. PLoS One 4:e5650

88. Buijs RM, Chun SJ, Niijima A, Romijn HJ, Nagai K. 2001. Parasympathetic and sympathetic control of the pancreas: a role for the suprachiasmatic nucleus and other hypothalamic centers that are involved in the regulation of food intake. F. Comp. Neurol. 431:405-23

89. Gerendai I, Toth IE, Boldogkoi Z, Medveczky I, Halasz B. 2000. CNS structures presumably involved in vagal control of ovarian function. 7. Auton. Nerv. Syst. 80:40-45

90. Kreier F, Fliers E, Voshol PJ, Van Eden CG, Havekes LM, et al. 2002. Selective parasympathetic innervation of subcutaneous and intra-abdominal fat-functional implications. F. Clin. Investig. 110:1243-50

91. la Fleur SE, Kalsbeek A, Wortel J, Buijs RM. 2000. Polysynaptic neural pathways between the hypothalamus, including the suprachiasmatic nucleus, and the liver. Brain Res. 871:50-56

92. Kalsbeek A, Palm IF, La Fleur SE, Scheer FA, Perreau-Lenz S, et al. 2006. SCN outputs and the hypothalamic balance of life. F. Biol. Rhythms 21:458-69

93. Caldelas I, Poirel VJ, Sicard B, Pevet P, Challet E. 2003. Circadian profile and photic regulation of clock genes in the suprachiasmatic nucleus of a diurnal mammal Arvicantbis ansorgei. Neuroscience 116:583-91

94. Mrosovsky N, Edelstein K, Hastings MH, Maywood ES. 2001. Cycle of period gene expression in a diurnal mammal (Spermophilus tridecemlineatus): implications for nonphotic phase shifting. F. Biol. Rhythms $16: 471-78$

95. Tournier BB, Dardente H, Vuillez P, Pevet P, Challet E. 2007. Expression of TGF $\alpha$ in the suprachiasmatic nuclei of nocturnal and diurnal rodents. Neuroscience 145:1138-43

96. Vosko AM, Hagenauer MH, Hummer DL, Lee TM. 2009. Period gene expression in the diurnal degu (Octodon degus) differs from the nocturnal laboratory rat (Rattus norvegicus). Am. F. Physiol. Regul. Integr. Comp. Physiol. 296:R353-61

97. Tosini G, Menaker M. 1996. Circadian rhythms in cultured mammalian retina. Science 272:419-21

98. Tosini G, Menaker M. 1998. The tau mutation affects temperature compensation of hamster retinal circadian oscillators. NeuroReport 9:1001-5

99. Dudley CA, Erbel-Sieler C, Estill SJ, Reick M, Franken P, et al. 2003. Altered patterns of sleep and behavioral adaptability in NPAS2-deficient mice. Science 301:379-83

100. Reick M, Garcia JA, Dudley C, McKnight SL. 2001. NPAS2: an analog of clock operative in the mammalian forebrain. Science 293:506-9

101. DeBruyne JP, Weaver DR, Reppert SM. 2007. CLOCK and NPAS2 have overlapping roles in the suprachiasmatic circadian clock. Nat. Neurosci. 10:543-45

102. Feillet CA, Mendoza J, Albrecht U, Pevet P, Challet E. 2008. Forebrain oscillators ticking with different clock hands. Mol. Cell Neurosci. 37:209-21

103. Guilding C, Piggins HD. 2007. Challenging the omnipotence of the suprachiasmatic timekeeper: Are circadian oscillators present throughout the mammalian brain? Eur. F. Neurosci. 25:3195-216 
104. Abe M, Herzog ED, Yamazaki S, Straume M, Tei H, et al. 2002. Circadian rhythms in isolated brain regions. F. Neurosci. 22:350-56

105. Abraham U, Prior JL, Granados-Fuentes D, Piwnica-Worms DR, Herzog ED. 2005. Independent circadian oscillations of Period1 in specific brain areas in vivo and in vitro. F. Neurosci. 25:8620-26

106. Balsalobre A, Damiola F, Schibler U. 1998. A serum shock induces circadian gene expression in mammalian tissue culture cells. Cell 93:929-37

107. Nagoshi E, Saini C, Bauer C, Laroche T, Naef F, Schibler U. 2004. Circadian gene expression in individual fibroblasts: cell-autonomous and self-sustained oscillators pass time to daughter cells. Cell 119:693-705

108. Granados-Fuentes D, Prolo LM, Abraham U, Herzog ED. 2004. The suprachiasmatic nucleus entrains, but does not sustain, circadian rhythmicity in the olfactory bulb. F. Neurosci. 24:615-19

109. Magistretti PJ, Sorg O, Naichen Y, Pellerin L, de Rham S, Martin JL. 1994. Regulation of astrocyte energy metabolism by neurotransmitters. Ren. Physiol. Biochem. 17:168-71

110. Cheng HY, Alvarez-Saavedra M, Dziema H, Choi YS, Li A, Obrietan K. 2009. Segregation of expression of mPeriod gene homologs in neurons and glia: possible divergent roles of mPeriod 1 and $\mathrm{mPeriod} 2$ in the brain. Hum. Mol. Genet. 18:3110-24

111. Zheng B, Albrecht U, Kaasik K, Sage M, Lu W, et al. 2001. Nonredundant roles of the mPer1 and mPer2 genes in the mammalian circadian clock. Cell 105:683-94

112. Spanagel R, Pendyala G, Abarca C, Zghoul T, Sanchis-Segura C, et al. 2005. The clock gene Per2 influences the glutamatergic system and modulates alcohol consumption. Nat. Med. 11:35-42

113. Quintero JE, Kuhlman SJ, McMahon DG. 2003. The biological clock nucleus: a multiphasic oscillator network regulated by light. F. Neurosci. 23:8070-76

114. Maywood ES, Reddy AB, Wong GK, O’Neill JS, O’Brien JA, et al. 2006. Synchronization and maintenance of timekeeping in suprachiasmatic circadian clock cells by neuropeptidergic signaling. Curr. Biol. 16:599-605

115. Brown TM, Colwell CS, Waschek JA, Piggins HD. 2007. Disrupted neuronal activity rhythms in the suprachiasmatic nuclei of vasoactive intestinal polypeptide-deficient mice. F. Neurophysiol. 97:2553-58

116. Cutler DJ, Haraura M, Reed HE, Shen S, Sheward WJ, et al. 2003. The mouse VPAC2 receptor confers suprachiasmatic nuclei cellular rhythmicity and responsiveness to vasoactive intestinal polypeptide in vitro. Eur. F. Neurosci. 17:197-204

117. Pakhotin P, Harmar AJ, Verkhratsky A, Piggins H. 2006. VIP receptors control excitability of suprachiasmatic nuclei neurones. Pflugers Arch. 452:7-15

118. Yamazaki S, Kerbeshian MC, Hocker CG, Block GD, Menaker M. 1998. Rhythmic properties of the hamster suprachiasmatic nucleus in vivo. F. Neurosci. 18:10709-23

119. Zhao H, Rusak B. 2005. Circadian firing-rate rhythms and light responses of rat habenular nucleus neurons in vivo and in vitro. Neuroscience 132:519-28

120. Qu T, Dong K, Sugioka K, Yamadori T. 1996. Demonstration of direct input from the retina to the lateral habenular nucleus in the albino rat. Brain Res. 709:251-58

121. Parent A, Gravel S, Boucher R. 1981. The origin of forebrain afferents to the habenula in rat, cat and monkey. Brain Res. Bull. 6:23-38

122. Amat J, Sparks PD, Matus-Amat P, Griggs J, Watkins LR, Maier SF. 2001. The role of the habenular complex in the elevation of dorsal raphe nucleus serotonin and the changes in the behavioral responses produced by uncontrollable stress. Brain Res. 917:118-26

123. Herkenham M, Nauta WJ. 1979. Efferent connections of the habenular nuclei in the rat. F. Comp. Neurol. 187:19-47

124. Rønnekleiv OK, Møller M. 1979. Brain-pineal nervous connections in the rat: an ultrastructure study following habenular lesion. Exp. Brain Res. 37:551-62

125. Tavakoli-Nezhad M, Schwartz WJ. 2006. Hamsters running on time: Is the lateral habenula a part of the clock? Chronobiol. Int. 23:217-24

126. Abarca C, Albrecht U, Spanagel R. 2002. Cocaine sensitization and reward are under the influence of circadian genes and rhythm. Proc. Natl. Acad. Sci. USA 99:9026-30

127. Baird TJ, Gauvin D. 2000. Characterization of cocaine self-administration and pharmacokinetics as a function of time of day in the rat. Pharmacol. Biochem. Behav. 65:289-99 
128. Jones EM, Knutson D, Haines D. 2003. Common problems in patients recovering from chemical dependency. Am. Fam. Physician. 68:1971-78

129. Raymond RC, Warren M, Morris RW, Leikin JB. 1992. Periodicity of presentations of drugs of abuse and overdose in an emergency department. 7. Toxicol. Clin. Toxicol. 30:467-78

130. Wasielewski JA, Holloway FA. 2001. Alcohol's interactions with circadian rhythms. A focus on body temperature. Alcohol. Res. Health 25:94-100

131. McGrath RE, Yahia M. 1993. Preliminary data on seasonally related alcohol dependence. F. Clin. Psychiatry 54:260-62

132. Wirz-Justice A, Richter R. 1979. Seasonality in biochemical determinations: a source of variance and a clue to the temporal incidence of affective illness. Psychiatry Res. 1:53-60

133. Shibley HL, Malcolm RJ, Veatch LM. 2008. Adolescents with insomnia and substance abuse: consequences and comorbidities. F. Psychiatr. Pract. 14:146-53

134. Rosenwasser AM, Fecteau ME, Logan RW. 2005. Effects of ethanol intake and ethanol withdrawal on free-running circadian activity rhythms in rats. Physiol. Behav. 84:537-42

135. Sanchis-Segura C, Spanagel R. 2006. Behavioural assessment of drug reinforcement and addictive features in rodents: an overview. Addict. Biol. 11:2-38

136. Yuferov V, Kroslak T, Laforge KS, Zhou Y, Ho A, Kreek MJ. 2003. Differential gene expression in the rat caudate putamen after "binge" cocaine administration: advantage of triplicate microarray analysis. Synapse 48:157-69

137. Uz T, Ahmed R, Akhisaroglu M, Kurtuncu M, Imbesi M, et al. 2005. Effect of fluoxetine and cocaine on the expression of clock genes in the mouse hippocampus and striatum. Neuroscience 134:1309-16

138. Lüscher C. 2007. Drugs of abuse. In Basic and Clinical Pharmacology, ed. BG Katzung, pp. 511-25. New York: McGraw-Hill

139. Nestler EJ, Carlezon WAJr. 2006. The mesolimbic dopamine reward circuit in depression. Biol. Psychiatry 59:1151-59

140. Witkovsky P. 2004. Dopamine and retinal function. Doc. Ophthalmol. 108:17-40

141. Doi M, Yujnovsky I, Hirayama J, Malerba M, Tirotta E, et al. 2006. Impaired light masking in dopamine D2 receptor-null mice. Nat. Neurosci. 9:732-34

142. Yujnovsky I, Hirayama J, Doi M, Borrelli E, Sassone-Corsi P. 2006. Signaling mediated by the dopamine D2 receptor potentiates circadian regulation by CLOCK:BMAL1. Proc. Natl. Acad. Sci. USA 103:638691

143. McClung CA, Sidiropoulou K, Vitaterna M, Takahashi JS, White FJ, et al. 2005. Regulation of dopaminergic transmission and cocaine reward by the Clock gene. Proc. Natl. Acad. Sci. USA 102:9377-81

144. Roybal K, Theobold D, Graham A, DiNieri JA, Russo SJ, et al. 2007. Mania-like behavior induced by disruption of CLOCK. Proc. Natl. Acad. Sci. USA 104:6406-11

145. Hampp G, Ripperger JA, Houben T, Schmutz I, Blex C, et al. 2008. Regulation of monoamine oxidase A by circadian-clock components implies clock influence on mood. Curr. Biol. 18:678-83

146. Partonen T, Treutlein J, Alpman A, Frank J, Johansson C, et al. 2007. Three circadian clock genes Per2, Arntl, and Npas2 contribute to winter depression. Ann. Med. 39:229-38

147. Honma K, Honma S, Hiroshige T. 1986. Disorganization of the rat activity rhythm by chronic treatment with methamphetamine. Physiol. Behav. 38:687-95

148. Honma K, Honma S, Hiroshige T. 1987. Activity rhythms in the circadian domain appear in suprachiasmatic nuclei lesioned rats given methamphetamine. Physiol. Behav. 40:767-74

149. Honma S, Yasuda T, Yasui A, van der Horst GT, Honma K. 2008. Circadian behavioral rhythms in Cry1/Cry2 double-deficient mice induced by methamphetamine. F. Biol. Rhythms 23:91-94

150. Masubuchi S, Honma S, Abe H, Nakamura W, Honma K. 2001. Circadian activity rhythm in methamphetamine-treated Clock mutant mice. Eur. F. Neurosci. 14:1177-80

151. Tataroglu O, Davidson AJ, Benvenuto LJ, Menaker M. 2006. The methamphetamine-sensitive circadian oscillator (MASCO) in mice. 7. Biol. Rhythms 21:185-94

152. Nikaido T, Akiyama M, Moriya T, Shibata S. 2001. Sensitized increase of period gene expression in the mouse caudate/putamen caused by repeated injection of methamphetamine. Mol. Pharmacol. 59:894-900 
153. Iijima M, Nikaido T, Akiyama M, Moriya T, Shibata S. 2002. Methamphetamine-induced, suprachiasmatic nucleus-independent circadian rhythms of activity and mPer gene expression in the striatum of the mouse. Eur. 7. Neurosci. 16:921-29

154. Yamamoto H, Imai K, Takamatsu Y, Kamegaya E, Kishida M, et al. 2005. Methamphetamine modulation of gene expression in the brain: analysis using customized cDNA microarray system with the mouse homologues of KIAA genes. Brain Res. Mol. Brain Res. 137:40-46

155. Hampp G, Albrecht U. 2008. The circadian clock and mood-related behavior. Commun. Integr. Biol. $1: 1-3$

156. Mohawk JA, Baer ML, Menaker M. 2009. The methamphetamine-sensitive circadian oscillator does not employ canonical clock genes. Proc. Natl. Acad. Sci. USA 106:3519-24

157. Hsu YH, Chen CC, Zechariah A, Yen CC, Yang LC, Chang C. 2008. Neuronal dysfunction of a long projecting multisynaptic pathway in response to methamphetamine using manganese-enhanced MRI. Psychopharmacology 196:543-53

158. Matsumoto M, Hikosaka O. 2007. Lateral habenula as a source of negative reward signals in dopamine neurons. Nature 447:1111-15

159. Schultz W. 2002. Getting formal with dopamine and reward. Neuron 36:241-63

160. Boulos Z, Terman M. 1980. Food availability and daily biological rhythms. Neurosci. Biobehav. Rev. 4:11931

161. Mistlberger RE. 1994. Circadian food-anticipatory activity: formal models and physiological mechanisms. Neurosci. Biobehav. Rev. 18:171-95

162. Stephan FK. 2002. The "other" circadian system: food as a Zeitgeber. F. Biol. Rhythms 17:284-92

163. Stephan FK, Swann JM, Sisk CL. 1979. Entrainment of circadian rhythms by feeding schedules in rats with suprachiasmatic lesions. Behav. Neural Biol. 25:545-54

164. Davidson AJ, Cappendijk SL, Stephan FK. 2000. Feeding-entrained circadian rhythms are attenuated by lesions of the parabrachial region in rats. Am. F. Physiol. Regul. Integr. Comp. Physiol. 278:R1296-304

165. Mistlberger RE, Mumby DG. 1992. The limbic system and food-anticipatory circadian rhythms in the rat: ablation and dopamine blocking studies. Behav. Brain Res. 47:159-68

166. LeSauter J, Hoque N, Weintraub M, Pfaff DW, Silver R. 2009. Stomach ghrelin-secreting cells as food-entrainable circadian clocks. Proc. Natl. Acad. Sci. USA 106:13582-87

167. Landry GJ, Simon MM, Webb IC, Mistlberger RE. 2006. Persistence of a behavioral food-anticipatory circadian rhythm following dorsomedial hypothalamic ablation in rats. Am. F. Physiol. Regul. Integr. Comp. Physiol. 290:R1527-34

168. Mieda M, Williams SC, Richardson JA, Tanaka K, Yanagisawa M. 2006. The dorsomedial hypothalamic nucleus as a putative food-entrainable circadian pacemaker. Proc. Natl. Acad. Sci. USA 103:12150-55

169. Feillet CA, Ripperger JA, Magnone MC, Dulloo A, Albrecht U, Challet E. 2006. Lack of food anticipation in Per2 mutant mice. Curr. Biol. 16:2016-22

170. Pitts S, Perone E, Silver R. 2003. Food-entrained circadian rhythms are sustained in arrhythmic Clk/Clk mutant mice. Am. F. Physiol. Regul. Integr. Comp. Physiol. 285:R57-67

171. Iijima M, Yamaguchi S, van dr Horst GT, Bonnefont X, Okamura H, Shibata S. 2005. Altered foodanticipatory activity rhythm in Cryptochrome-deficient mice. Neurosci. Res. 52:166-73

172. Pendergast JS, Nakamura W, Friday RC, Hatanaka F, Takumi T, Yamazaki S. 2009. Robust food anticipatory activity in BMAL1-deficient mice. PLoS One 4:e4860

173. Storch KF, Weitz CJ. 2009. Daily rhythms of food-anticipatory behavioral activity do not require the known circadian clock. Proc. Natl. Acad. Sci. USA 106:6808-13

174. Shearman LP, Sriram S, Weaver DR, Maywood ES, Chaves I, et al. 2000. Interacting molecular loops in the mammalian circadian clock. Science 288:1013-19

175. Hommel JD, Trinko R, Sears RM, Georgescu D, Liu ZW, et al. 2006. Leptin receptor signaling in midbrain dopamine neurons regulates feeding. Neuron 51:801-10

176. Fulton S, Pissios P, Manchon RP, Stiles L, Frank L, et al. 2006. Leptin regulation of the mesoaccumbens dopamine pathway. Neuron 51:811-22

177. Turek FW, Joshu C, Kohsaka A, Lin E, Ivanova G, et al. 2005. Obesity and metabolic syndrome in circadian Clock mutant mice. Science 308:1043-45 
178. Yamazaki S, Numano R, Abe M, Hida A, Takahashi R, et al. 2000. Resetting central and peripheral circadian oscillators in transgenic rats. Science 288:682-85

179. Yagita K, Tamanini F, van der Horst GT, Okamura H. 2001. Molecular mechanisms of the biological clock in cultured fibroblasts. Science 292:278-81

180. Yamamoto T, Nakahata Y, Soma H, Akashi M, Mamine T, Takumi T. 2004. Transcriptional oscillation of canonical clock genes in mouse peripheral tissues. BMC Mol. Biol. 5:18

181. Yamazaki S, Yoshikawa T, Biscoe EW, Numano R, Gallaspy LM, et al. 2009. Ontogeny of circadian organization in the rat. F. Biol. Rhythms 24:55-63

182. Yoo SH, Yamazaki S, Lowrey PL, Shimomura K, Ko CH, et al. 2004. PERIOD2::LUCIFERASE realtime reporting of circadian dynamics reveals persistent circadian oscillations in mouse peripheral tissues. Proc. Natl. Acad. Sci. USA 101:5339-46

183. Alvarez JD, Sehgal A. 2005. The thymus is similar to the testis in its pattern of circadian clock gene expression. 7. Biol. Rhythms 20:111-21

184. Liu S, Cai Y, Sothern RB, Guan Y, Chan P. 2007. Chronobiological analysis of circadian patterns in transcription of seven key clock genes in six peripheral tissues in mice. Chronobiol. Int. 24:793-820

185. Gachon F, Olela FF, Schaad O, Descombes P, Schibler U. 2006. The circadian PAR-domain basic leucine zipper transcription factors DBP, TEF, and HLF modulate basal and inducible xenobiotic detoxification. Cell Metab. 4:25-36

186. Lamia KA, Storch KF, Weitz CJ. 2008. Physiological significance of a peripheral tissue circadian clock. Proc. Natl. Acad. Sci. USA 105:15172-77

187. Le Martelot G, Claudel T, Gatfield D, Schaad O, Kornmann B, et al. 2009. REV-ERB $\alpha$ participates in circadian SREBP signaling and bile acid homeostasis. PLoS Biol. 7:e100018

188. Gachon F, Nagoshi E, Brown SA, Ripperger J, Schibler U. 2004. The mammalian circadian timing system: from gene expression to physiology. Chromosoma 113:103-12

189. Kornmann B, Schaad O, Reinke H, Saini C, Schibler U. 2007. Regulation of circadian gene expression in liver by systemic signals and hepatocyte oscillators. Cold Spring Harbor Symp. Quant. Biol. 72:319-30

190. Stratmann M, Schibler U. 2006. Properties, entrainment, and physiological functions of mammalian peripheral oscillators. F. Biol. Rhythms 21:494-506

191. Akhtar RA, Reddy AB, Maywood ES, Clayton JD, King VM, et al. 2002. Circadian cycling of the mouse liver transcriptome, as revealed by cDNA microarray, is driven by the suprachiasmatic nucleus. Curr. Biol. 12:540-50

192. Duffield GE, Best JD, Meurers BH, Bittner A, Loros JJ, Dunlap JC. 2002. Circadian programs of transcriptional activation, signaling, and protein turnover revealed by microarray analysis of mammalian cells. Curr. Biol. 12:551-57

193. Hughes ME, DiTacchio L, Hayes KR, Vollmers C, Pulivarthy S, et al. 2009. Harmonics of circadian gene transcription in mammals. PLoS Genet. 5:e1000442

194. Kornmann B, Schaad O, Bujard H, Takahashi JS, Schibler U. 2007. System-driven and oscillatordependent circadian transcription in mice with a conditionally active liver clock. PLoS Biol. 5:e34

195. McCarthy JJ, Andrews JL, McDearmon EL, Campbell KS, Barber BK, et al. 2007. Identification of the circadian transcriptome in adult mouse skeletal muscle. Physiol. Genomics 31:86-95

196. Miller BH, McDearmon EL, Panda S, Hayes KR, ZhangJ, et al. 2007. Circadian and CLOCK-controlled regulation of the mouse transcriptome and cell proliferation. Proc. Natl. Acad. Sci. USA 104:3342-47

197. Oishi K, Amagai N, Shirai H, Kadota K, Ohkura N, Ishida N. 2005. Genome-wide expression analysis reveals 100 adrenal gland-dependent circadian genes in the mouse liver. DNA Res. 12:191-202

198. Oishi K, Miyazaki K, Kadota K, Kikuno R, Nagase T, et al. 2003. Genome-wide expression analysis of mouse liver reveals CLOCK-regulated circadian output genes. F. Biol. Chem. 278:41519-27

199. Panda S, Hogenesch JB, Kay SA. 2002. Circadian rhythms from flies to human. Nature 417:329-35

200. Ueda HR, Chen W, Adachi A, Wakamatsu H, Hayashi S, et al. 2002. A transcription factor response element for gene expression during circadian night. Nature 418:534-39

201. Vander Heiden MG, Cantley LC, Thompson CB. 2009. Understanding the Warburg effect: the metabolic requirements of cell proliferation. Science 324:1029-33

202. Schibler U. 2007. The daily timing of gene expression and physiology in mammals. Dialog. Clin. Neurosci. $9: 257-72$ 
203. Ishikawa K, Shimazu T. 1980. Circadian rhythm of liver glycogen metabolism in rats: effects of hypothalamic lesions. Am. F. Physiol. 238:E21-25

204. Reddy AB, Karp NA, Maywood ES, Sage EA, Deery M, et al. 2006. Circadian orchestration of the hepatic proteome. Curr. Biol. 16:1107-15

205. Gatfield D, Le Martelot G, Vejnar CE, Gerlach D, Schaad O, et al. 2009. Integration of microRNA miR-122 in hepatic circadian gene expression. Genes Dev. 23:1313-26

206. Guo H, Brewer JM, Lehman MN, Bittman EL. 2006. Suprachiasmatic regulation of circadian rhythms of gene expression in hamster peripheral organs: effects of transplanting the pacemaker. 7 . Neurosci. 26:6406-12

207. Guo H, Brewer JM, Champhekar A, Harris RB, Bittman EL. 2005. Differential control of peripheral circadian rhythms by suprachiasmatic-dependent neural signals. Proc. Natl. Acad. Sci. USA 102:3111-16

208. Akashi M, Nishida E. 2000. Involvement of the MAP kinase cascade in resetting of the mammalian circadian clock. Genes Dev. 14:645-49

209. Brown SA, Fleury-Olela F, Nagoshi E, Hauser C, Juge C, et al. 2005. The period length of fibroblast circadian gene expression varies widely among human individuals. PLoS Biol. 3:e338

210. Welsh DK, Yoo SH, Liu AC, Takahashi JS, Kay SA. 2004. Bioluminescence imaging of individual fibroblasts reveals persistent, independently phased circadian rhythms of clock gene expression. Curr. Biol. 14:2289-95

211. Konopka RJ, Pittendrigh C, Orr D. 1989. Reciprocal behaviour associated with altered homeostasis and photosensitivity of Drosophila clock mutants. F. Neurogenet. 6:1-10

212. Pittendrigh CS. 1954. On temperature independence in the clock system controlling emergence time in Drosophila. Proc. Natl. Acad. Sci. USA 40:1018-29

213. Kaushik R, Nawathean P, Busza A, Murad A, Emery P, Rosbash M. 2007. PER-TIM interactions with the photoreceptor cryptochrome mediate circadian temperature responses in Drosophila. PLoS Biol. 5:e146

214. Takeuchi T, Hinohara T, Kurosawa G, Uchida K. 2007. A temperature-compensated model for circadian rhythms that can be entrained by temperature cycles. F. Theor. Biol. 246:195-204

215. Dibner C, Sage D, Unser M, Bauer C, d'Eysmond T, et al. 2009. Circadian gene expression is resilient to large fluctuations in overall transcription rates. EMBO F. 28:123-34

216. Izumo M, Johnson CH, Yamazaki S. 2003. Circadian gene expression in mammalian fibroblasts revealed by real-time luminescence reporting: temperature compensation and damping. Proc. Natl. Acad. Sci. USA 100:16089-94

217. Tsuchiya Y, Akashi M, Nishida E. 2003. Temperature compensation and temperature resetting of circadian rhythms in mammalian cultured fibroblasts. Genes Cells 8:713-20

218. Tomita J, Nakajima M, Kondo T, Iwasaki H. 2005. No transcription-translation feedback in circadian rhythm of KaiC phosphorylation. Science 307:251-54

219. Nakajima M, Imai K, Ito H, Nishiwaki T, Murayama Y, et al. 2005. Reconstitution of circadian oscillation of cyanobacterial KaiC phosphorylation in vitro. Science 308:414-15

220. Kitayama Y, Nishiwaki T, Terauchi K, Kondo T. 2008. Dual KaiC-based oscillations constitute the circadian system of cyanobacteria. Genes Dev. 22:1513-21

221. Gallego M, Virshup DM. 2007. Post-translational modifications regulate the ticking of the circadian clock. Nat. Rev. Mol. Cell Biol. 8:139-48

222. Lakin-Thomas PL. 2006. Transcriptional feedback oscillators: maybe, maybe not. F. Biol. Rhythms 21:8392

223. Fan Y, Hida A, Anderson DA, Izumo M, Johnson CH. 2007. Cycling of CRYPTOCHROME proteins is not necessary for circadian-clock function in mammalian fibroblasts. Curr. Biol. 17:1091-100

224. Liu AC, Welsh DK, Ko CH, Tran HG, Zhang EE, et al. 2007. Intercellular coupling confers robustness against mutations in the SCN circadian clock network. Cell 129:605-16

225. Schmidt EE, Schibler U. 1995. Cell size regulation, a mechanism that controls cellular RNA accumulation: consequences on regulation of the ubiquitous transcription factors Oct1 and NF-Y and the liver-enriched transcription factor DBP. F. Cell Biol. 128:467-83

226. Geyfman M, Andersen B. 2009. How the skin can tell time. 7. Investig. Dermatol. 129:1063-66

227. Lin KK, Kumar V, Geyfman M, Chudova D, Ihler AT, et al. 2009. Circadian clock genes contribute to the regulation of hair follicle cycling. PLoS Genet. 5:e1000573 
228. Brown SA, Kunz D, Dumas A, Westermark PO, Vanselow K, et al. 2008. Molecular insights into human daily behavior. Proc. Natl. Acad. Sci. USA 105:1602-7

229. Vanselow K, Vanselow JT, Westermark PO, Reischl S, Maier B, et al. 2006. Differential effects of PER2 phosphorylation: molecular basis for the human familial advanced sleep phase syndrome (FASPS). Genes Dev. 20:2660-72

230. Damiola F, Le Minh N, Preitner N, Kornmann B, Fleury-Olela F, Schibler U. 2000. Restricted feeding uncouples circadian oscillators in peripheral tissues from the central pacemaker in the suprachiasmatic nucleus. Genes Dev. 14:2950-61

231. Brown SA, Zumbrunn G, Fleury-Olela F, Preitner N, Schibler U. 2002. Rhythms of mammalian body temperature can sustain peripheral circadian clocks. Curr. Biol. 12:1574-83

232. Vujovic N, Davidson AJ, Menaker M. 2008. Sympathetic input modulates, but does not determine, phase of peripheral circadian oscillators. Am. 7. Physiol. Regul. Integr. Comp. Physiol. 295:R355-60

233. Stokkan KA, Yamazaki S, Tei H, Sakaki Y, Menaker M. 2001. Entrainment of the circadian clock in the liver by feeding. Science 291:490-93

234. Konturek SJ, Konturek JW, Pawlik T, Brzozowski T. 2004. Brain-gut axis and its role in the control of food intake. F. Physiol. Pharmacol. 55:137-54

235. Schibler U. 2009. The 2008 Pittendrigh/Aschoff lecture: peripheral phase coordination in the mammalian circadian timing system. F. Biol. Rhythms 24:3-15

236. Kaasik K, Lee CC. 2004. Reciprocal regulation of haem biosynthesis and the circadian clock in mammals. Nature 430:467-71

237. Rutter J, Reick M, McKnight SL. 2002. Metabolism and the control of circadian rhythms. Annu. Rev. Biochem. 71:307-31

238. Tu BP, McKnight SL. 2006. Metabolic cycles as an underlying basis of biological oscillations. Nat. Rev. Mol. Cell Biol. 7:696-701

239. Storch KF, Lipan O, Leykin I, Viswanathan N, Davis FC, et al. 2002. Extensive and divergent circadian gene expression in liver and heart. Nature 417:78-83

240. Walker JR, Hogenesch JB. 2005. RNA profiling in circadian biology. Methods Enzymol. 393:366-76

241. Rutter J, Reick M, Wu LC, McKnight SL. 2001. Regulation of clock and NPAS2 DNA binding by the redox state of NAD cofactors. Science 293:510-14

242. Asher G, Gatfield D, Stratmann M, Reinke H, Dibner C, et al. 2008. SIRT1 regulates circadian clock gene expression through PER2 deacetylation. Cell 134:317-28

243. Nakahata Y, Kaluzova M, Grimaldi B, Sahar S, Hirayama J, et al. 2008. The NAD ${ }^{+}$-dependent deacetylase SIRT1 modulates CLOCK-mediated chromatin remodeling and circadian control. Cell 134:329-40

244. Blander G, Guarente L. 2004. The Sir2 family of protein deacetylases. Annu. Rev. Biochem. 73:417-35

245. Dali-Youcef N, Lagouge M, Froelich S, Koehl C, Schoonjans K, Auwerx J. 2007. Sirtuins: the 'magnificent seven', function, metabolism and longevity. Ann. Med. 39:335-45

246. Cuninkova L, Brown SA. 2008. Peripheral circadian oscillators: interesting mechanisms and powerful tools. Ann. NY Acad. Sci. 1129:358-70

247. Lahiri K, Vallone D, Gondi SB, Santoriello C, Dickmeis T, Foulkes NS. 2005. Temperature regulates transcription in the zebrafish circadian clock. PLoS Biol. 3:e351

248. Reinke H, Saini C, Fleury-Olela F, Dibner C, Benjamin IJ, Schibler U. 2008. Differential display of DNA-binding proteins reveals heat-shock factor 1 as a circadian transcription factor. Genes Dev. 22:33145

249. Oster H, Damerow S, Kiessling S, Jakubcakova V, Abraham D, et al. 2006. The circadian rhythm of glucocorticoids is regulated by a gating mechanism residing in the adrenal cortical clock. Cell Metab. 4:163-73

250. Balsalobre A, Brown SA, Marcacci L, Tronche F, Kellendonk C, et al. 2000. Resetting of circadian time in peripheral tissues by glucocorticoid signaling. Science 289:2344-47

251. Le Minh N, Damiola F, Tronche F, Schutz G, Schibler U. 2001. Glucocorticoid hormones inhibit food-induced phase-shifting of peripheral circadian oscillators. EMBO 7. 20:7128-36

252. Kalsbeek A, Foppen E, Schalij I, Van Heijningen C, Van Der Vliet J, et al. 2008. Circadian control of the daily plasma glucose rhythm: an interplay of GABA and glutamate. PLoS One 3:e3194 
253. Green CB, Takahashi JS, Bass J. 2008. The meter of metabolism. Cell 134:728-42

254. Prasai MJ, George JT, Scott EM. 2008. Molecular clocks, type 2 diabetes and cardiovascular disease. Diabet. Vasc. Dis. Res. 5:89-95

255. Englund A, Kovanen L, Saarikoski ST, Haukka J, Reunanen A, et al. 2009. NPAS2 and PER2 are linked to risk factors of the metabolic syndrome. F. Circadian Rhytbms 7:5

256. Mulder H, Nagorny CL, Lyssenko V, Groop L. 2009. Melatonin receptors in pancreatic islets: good morning to a novel type 2 diabetes gene. Diabetologia 52:1240-49

257. Peschke E. 2008. Melatonin, endocrine pancreas and diabetes. F. Pineal. Res. 44:26-40

258. Bouatia-Naji N, Bonnefond A, Cavalcanti-Proença C, Sparsø T, Holmkvist J, et al. 2009. A variant near MTNR1B is associated with increased fasting plasma glucose levels and type 2 diabetes risk. Nat. Genet. 41:89-94

259. Lyssenko V, Nagorny CL, Erdos MR, Wierup N, Jonsson A, et al. 2009. Common variant in MTNR1B associated with increased risk of type 2 diabetes and impaired early insulin secretion. Nat. Genet. 41:82-88

260. Muhlbauer E, Gross E, Labucay K, Wolgast S, Peschke E. 2009. Loss of melatonin signalling and its impact on circadian rhythms in mouse organs regulating blood glucose. Eur. F. Pharmacol. 606:61-71

261. O'Neill JS, Hastings MH. 2007. Circadian clocks: timely interference by microRNAs. Curr. Biol. 17:R760-62

262. Dodd AN, Salathia N, Hall A, Kevei E, Toth R, et al. 2005. Plant circadian clocks increase photosynthesis, growth, survival, and competitive advantage. Science 309:630-33

263. Ouyang Y, Andersson CR, Kondo T, Golden SS, Johnson CH. 1998. Resonating circadian clocks enhance fitness in cyanobacteria. Proc. Natl. Acad. Sci. USA 95:8660-64

264. Woelfle MA, Ouyang Y, Phanvijhitsiri K, Johnson CH. 2004. The adaptive value of circadian clocks: an experimental assessment in cyanobacteria. Curr. Biol. 14:1481-86

265. Loudon AS, Meng QJ, Maywood ES, Bechtold DA, Boot-Handford RP, Hastings MH. 2007. The biology of the circadian Ck1 $\varepsilon$ tau mutation in mice and Syrian hamsters: a tale of two species. Cold Spring Harbor Symp. Quant. Biol. 72:261-71

266. Levi FA. 2008. The circadian timing system: a coordinator of life processes: chronobiological investigations. Implications for the rhythmic delivery of cancer therapeutics. IEEE Eng. Med. Biol. Mag. 27:17-19 
R

\section{Contents}

Annual Review of Physiology

Volume 72, 2010

PERSPECTIVES, David Fulius, Editor

A Conversation with Rita Levi-Montalcini

Moses V. Chao

CARDIOVASCULAR PHYSIOLOGY, feffrey Robbins, Section Editor

Protein Conformation-Based Disease: Getting to the Heart of the

Matter

David Terrell and Feffrey Robbins

Cell Death in the Pathogenesis of Heart Disease: Mechanisms and Significance

Russell S. Whelan, Vladimir Kaplinskiy, and Richard N. Kitsis

Autophagy During Cardiac Stress: Joys and Frustrations of Autophagy

Roberta A. Gottlieb and Robert M. Mentzer, Fr.

The Cardiac Mitochondrion: Nexus of Stress

Christopher P. Baines

The FoxO Family in Cardiac Function and Dysfunction

Sarab M. Ronnebaum and Cam Patterson .81

CELL PHYSIOLOGY, David E. Clapham, Associate and Section Editor

Chloride Channels: Often Enigmatic, Rarely Predictable Charity Duran, Christopher H. Thompson, Qinghuan Xiao, and H. Criss Hartzell ....995

ECOLOGICAL, EVOLUTIONARY, AND COMPARATIVE PHYSIOLOGY, Martin E. Feder, Section Editor

Physiology and Global Climate Change Martin E. Feder

Living in the Now: Physiological Mechanisms to Tolerate a

Rapidly Changing Environment

Gretchen E. Hofmann and Anne E. Todgham 
Light, Time, and the Physiology of Biotic Response to Rapid Climate Change in Animals

William E. Bradshaw and Christina M. Holzapfel

Locomotion in Response to Shifting Climate Zones: Not So Fast

Martin E. Feder, Theodore Garland, Fr., Fames H. Marden, and Anthony 7. Zera ....

ENDOCRINOLOGY, Holly A. Ingraham, Section Editor

Genomic Analyses of Hormone Signaling and Gene Regulation Edwin Cheung and W. Lee Kraus

Macrophages, Inflammation, and Insulin Resistance

Ferrold M. Olefsky and Christopher K. Glass ....

Structural Overview of the Nuclear Receptor Superfamily: Insights into Physiology and Therapeutics

Pengxiang Huang, Vikas Chandra, and Fraydoon Rastinejad

GASTROINTESTINAL PHYSIOLOGY, fames M. Anderson, Section Editor

Apical Recycling of the Gastric Parietal Cell H,K-ATPase

Fobn G. Forte and Lixin Zhu ....

Role of Colonic Short-Chain Fatty Acid Transport in Diarrhea

Henry 7. Binder

The Biogenesis of Chylomicrons

Charles M. Mansbach and Shadab A. Siddiqi

NEUROPHYSIOLOGY, Roger Nicoll, Section Editor

Integrated Brain Circuits: Astrocytic Networks Modulate Neuronal

Activity and Behavior

Michael M. Halassa and Philip G. Haydon

RENAL AND ELECTROLYTE PHYSIOLOGY, Gerhard H. Giebisch, Section Editor

Cellular Maintenance and Repair of the Kidney

Fian-Kan Guo and Lloyd G. Cantley....

Intrarenal Purinergic Signaling in the Control of Renal Tubular

Transport

Helle A. Praetorius and fens Leipziger

The Physiological Significance of the Cardiotonic

Steroid/Ouabain-Binding Site of the Na,K-ATPase

Ferry B Lingrel 395 
RESPIRATORY PHYSIOLOGY, Richard C. Boucher, Fr., Section Editor

Inducible Innate Resistance of Lung Epithelium to Infection Scott E. Evans, Yi Xu, Michael 7. Tuvim, and Burton F. Dickey.

It's Not All Smooth Muscle: Non-Smooth-Muscle Elements in Control of Resistance to Airflow

Ynuk Bossé, Erik P. Riesenfeld, Peter D. Paré, and Charles G. Irvin

Regulation of Endothelial Permeability via Paracellular and

Transcellular Transport Pathways

Yulia Komarova and Asrar B. Malik

$\mathrm{T}_{\mathrm{H}} 17$ Cells in Asthma and COPD

Jobn F. Alcorn, Christopher R. Crowe, and Jay K. Kolls

\section{SPECIAL TOPIC, CELLULAR AND MOLECULAR MECHANISMS \\ OF CIRCADIAN CLOCKS IN ANIMALS, Joseph S. Takabasbi, Special Topic Editor}

The Mammalian Circadian Timing System: Organization and Coordination of Central and Peripheral Clocks Charna Dibner, Ueli Schibler, and Urs Albrecht

Suprachiasmatic Nucleus: Cell Autonomy and Network Properties David K. Welsh, Joseph S. Takahashi, and Steve A. Kay

Systems Biology of Mammalian Circadian Clocks Hideki Ukai and Hiroki R. Ueda. ...

Circadian Organization of Behavior and Physiology in Drosophila

Ravi Allada and Brian Y. Chung . ....

Mammalian Per-Arnt-Sim Proteins in Environmental Adaptation Brian E. McIntosh, John B. Hogenesch, and Christopher A. Bradfield ....

\section{Indexes}

Cumulative Index of Contributing Authors, Volumes 68-72 647

Cumulative Index of Chapter Titles, Volumes 68-72

\section{Errata}

An online log of corrections to Annual Review of Physiology articles may be found at http://physiol.annualreviews.org/errata.shtml 